NBSIR 80-2055

\title{
The Use of Acoustic Emission to Determine the Integrity of Large Hybrid Packages
}

G. G. Harman

Electron Devices Division

Center for Electronics and Electrical Engineering

National Engineering Laboratory

National Bureau of Standards

U.S. Department of Commerce

Washington, DC 20234

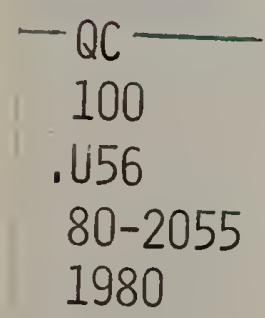

Prepared tor

Naval Avionics Center

Indianapolis, IN 46218 

G. G. Harman

\section{Electron Devices Division}

Center for Electronics and Electrical Engineering

National Engineering Laboratory

National Bureau of Standards

U.S. Department of Commerce

Washington, DC 20234

June 1980

\section{Prepared for}

Naval Avionics Center

Indianapolis, IN 46218

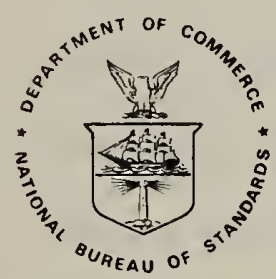

U.S. DEPARTMENT OF COMMERCE, Philip M. Klutznick, Secretary Luther H. Hodges, Jr., Deputy Secretary Jordan J. Baruch, Assistant Secretary for Productivity. Technology, and Innovation NATIONAL BUREAU OF STANDARDS, Ernest Ambler, Director 

Table of Contents

Page

Abstract . . . . . . . . . . . . . . . . . . . . 1

1. Introduction . . . . . . . . . . . . . . . . . 1

2. The Effects of Avionics Environmental Vibration on the Seals of PC Board-Mounted Hybrid Packages . . . . . . . . . . . . 2

2.1 Theoretical Considerations . . . . . . . . . . . . 2

2.2 PC Board Layout Considerations . . . . . . . . . . . 6

2.3 Experimental Measurements . . . . . . . . . . . . 7

2.3.1 The Experimental Setup and Vibration of Unloaded PC

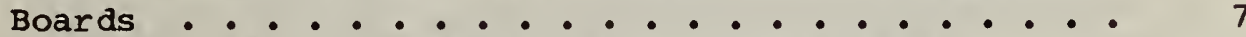

2.3.2 Vibration of PC Board-Mounted Hybrid Packages . . . 11

3. Development of an Acoustic Emission Detector Resistant to Vibration-Induced Cable Noise and Sensitive to Surface Waves . .

4. Development of a High-Temperature Open-Package Leak Test Procedure

5. Development of an AE-Monitored Thermal Shock Test . . . . . .

6. Determining the Susceptibility of the Kovar Glass Seal to Damage During Bonding ........................

6.1 Mechanical Characteristics of Kovar Glass Packages . . . .

6.2 Acoustic Emission Tests to Determine Glass-Seal Damage . . .

Acknow ledgment . . . . . . . . . . . . . . . . 30

References . . . . . . . . . . . . . . . . . 32

Appendix . . . . . . . . . . . . . . . . . . 34

List of Figures

1. Sketch of fixed boundary conditions . . . . . . . . . . 3

2. Sketch of supported boundary conditions . . . . . . . . . 3

3. Sketch identifying dimensions of a vibrating plate . . . . . 3

4. Pictorial examples of the first several vibration modes of rec-

tangular boards .................... . 5

5. An overview of the vibration equipment ........... 8

6. A closeup of the vibration shaker unit, showing the PC board

"fixed" mount, and a PC board with four hybrids on it...... 
7. The sinusoidal vibration requirements for equipment designed for installation in jet airplanes ...............

8. The resonant vibration peaks on a 20-min frequency sweep of a PC board ..........................

9. Photomicrographs of a 1-in. square hybrid package after vibration testing... . . . . . . . . . . . . . . . . .

10. Steps in the assembly of the TO-100 acoustic emission detector amplifier . . . . . . . . . . . . . . . . . .

11. Frequency response curve of a PZT AE detector . . . . . . .

12. The high-temperature open package leak test apparatus . . . .

13. Thermal shock hot stage with a hybrid package and a water-cooled AE detector on top .......................

14. Temperature rise curves for a hybrid package on the hot stage of figure 13 . . . . . . . . . . . . . . . . . .

15. Sketch showing beam-bending variables . . . . . . . . .

16. A force-probe apparatus used to simulate bonding forces on hybrid leaks... . . . . . . . . . . . . . . . . .

17. A closeup of the force probe, hybrid, and TO-100 AE detector . . 26

18. Block diagram of $\mathrm{AE}$ measurement equipment . . . . . . . . . 28

19. Acoustic emission burst from glass cracking due to a force of 45 gf applied to the internal lead .................

20. A large acoustic emission burst resulting from a small sliver of glass cracking off from the bottom side of the lead resulting in a loose particle .....................

21. An $A E$ burst at 25 gf applied to the lead from a seal that was damaged on the outside with no damage observed on the inner side

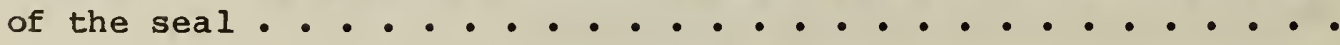

List of Tables

1. Calculated Modal Frequencies for Two PC Boards . . . . . . . 6

2. Comparison Between Calculated and Measured Modal Frequencies • - 11

3. Measured Thicknesses of Hybrid Package Leads . . . . . . . . . 24

4. Comparison Between Measured and Calculated Bending of Kovar Leads 25 
The Use of Acoustic Emission to Determine the Integrity of Large Hybrid Packages

\author{
G. G. Harman \\ Electron Devices Division \\ National Bureau of Standards \\ Washington, DC 20234
}

\begin{abstract}
The general objective of the program was to develop tests to determine the integrity of large hybrid packages under various thermal and mechanical stresses that may be encountered during assembly, during installation in systems, or in operation. Several measurement techniques are being investigated, but emphasis is placed on acoustic emission test procedures. The specific objectives studied during the initial period were: (1) determination of the effects of avionics environmental vibration on the seals of hybrid packages mounted on printed-circuit (PC) boards; (2) development of an acoustic emission detector sensitive to surface waves, but insensitive to vibration-induced cable noise; (3) development of a hightemperature $\left(125^{\circ} \mathrm{C}\right)$ open-package helium leak test to observe marginal seal damage; (4) development of an acoustic emission test for inspection of hybrid packages during high-temperature thermal shock; and (5) determination of possible damage to seals during thermocompression and thermosonic bonding, during lead forming, and during other assembly operations.
\end{abstract}

\title{
1. INTRODUCTION
}

The general objective of the Program was to develop tests to determine the integrity of large hybrid packages under various thermal and mechanical stresses that they may encounter during assembly, during installation in systems, or in operation. Several measurement techniques are being investigated, but emphasis is placed on acoustic emission test procedures.

Acoustic emission ( $A E$ ) detection was used as a major measurement tool in the program. Acoustic emission is generally defined as being a transient elastic wave or stress wave generated by the rapid release of energy within a material when that material undergoes fracture or deformation. The emitted stress waves may have frequencies ranging from the audible into the megahertz region, but the maximum energy is usually concentrated in the mechanical resonance modes of the test specimen. Detection of these stress waves usually takes place with ceramic piezoelectric transducers that are acoustically coupled to the specimen.

When $\mathrm{AE}$ is used to detect cracks in specimens of a size typical of electronic components, investigators usually attach a transducer, which may be larger than the specimen, in whatever manner is possible (such as using tapered acoustic waveguides) and work with whatever signal is received. Waveform signatures, of frequency and amplitude, are recorded and empirically correlated with appropriate mechanical stress tests (e.g., destructive pull tests) for interpretation. 
Two books provide a more complete description of AE theory, of the equipment used in $A E$ tests, and of applications of $A E$ to a variety of nonelectronic problems $[1,2]$. A recently published report by Harman gives an introduction to $A E$ as well as a review of the applications of acoustic emission in the electronics field [3].

\section{THE EFFECTS OF AVIONICS ENVIRONMENTAL VIBRATION ON THE SEALS OF PC BOARD-MOUNTED HYBRID PACKAGES}

An investigation was initiated to study possible detrimental effects on printed-circuit (PC) board-mounted hybrid microcircuit seals in an avionics vibration environment. To accomplish this, various examples of flat-pack and plug-in hybrids were soldered into PC boards and run through appropriate vibration tests specified in MIL-E-5400R (Electronic Equipment, Airborne, General specification for). Damage to seals, revealed by visual inspection and acoustic emission measurements, was assessed and correlated with helium leak test measurements made at normal and at high temperatures.

Before actual vibration tests began, it was necessary to conduct a literature search in order to avoid repeating any earlier experiments. This was done both in the NBS library and at the DoD Shock and Vibration Information Center. It turned out that most of the relevant work on vibration of electronic components and systems had been done a number of years ago. The emphasis in all cases was on obvious flexure fatigue damage to the PC board or to the wire leads of components soldered to it. In no case have there been reported any studies of more subtle damage to components, such as damage to glassmetal seals, although the possibility of cracked glass seals was suggested in one recent paper [4] without photographs or other supporting evidence. The most convenient and complete single reference to vibration effects on electronic systems is a book by Steinberg [5] which has a chapter on the vibration of PC boards and other chapters on the fatigue of wire leads in components. Steinberg has also written a series of simplified but useful articles in trade magazines [6-11], most of which appear to be derived from his book. other relevant papers in the archival literature or presented in conferences [12-16] were also reviewed. In all of these references, the resonant frequency calculations for PC boards were based on simplified equations and were limited to the lowest (the "natural") vibration mode, which is typically in the 100 - to $300-\mathrm{Hz}$ range. Since the vibration requirements in MIL-E-5400R extend to $2000 \mathrm{~Hz}$, it was necessary to use more complex equations to obtain correlations with actual vibration measurements and to be able to locate relatively benigm component mounting positions on PC boards.

\subsection{Theoretical Considerations}

The vibration modes of a printed circuit board may be obtained if the board is modeled as a vibrating plate. Various equations for the vibration modes of plates and membranes having specified boundary conditions have been derived in the literature [17-20]. The most commonly used mathematical methods were set forth by Rayleigh [21]. The boundary conditions are the dominating factor in determining modal frequencies; different conditions can result in frequencies which differ by an order of magnitude. 
The three boundary conditions appropriate to PC boards are fixed, supported, and free. For the fixed conditions, sketched in figure 1, the board edges are firmly clamped such that the edge motion is zero and the tangent is also zero. The term "supported" (also referred to as simply supported or freely supported) is a carryover from beam-bending theory where the ends of the beam are supported on knife edges. For a PC board, each edge is considered supported between two knife edges. In this case, motion at the edge supports is zero but the tangent is not constrained, as shown in figure 2 .

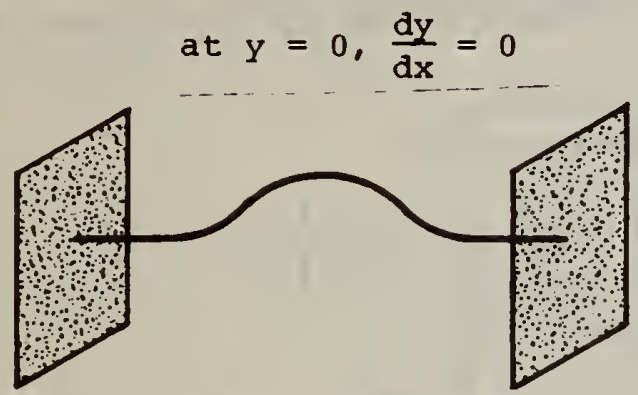

Figure 1. Sketch of fixed boundary conditions. at $y=0, \frac{d y}{d x} \neq 0$

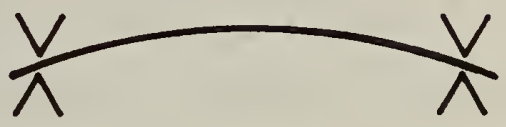

Figure 2. Sketch of supported boundary conditions.

The resonant frequencies of fixed boards are significantly higher than those of supported ones because the fixed mount effectively reduces the length of board available for vibration. The free case will not be considered here since all PC boards used in avionics are clamped or supported in some manner. As stated earlier, previous work analyzed PC boards using simplified equations which did not perinit calculation of higher resonant modes. In the present work, general equations were derived using, as a basis, the models of Warburton [18] and Hearmon [20]. The dimensions used in the equations are identified in figure 3 .

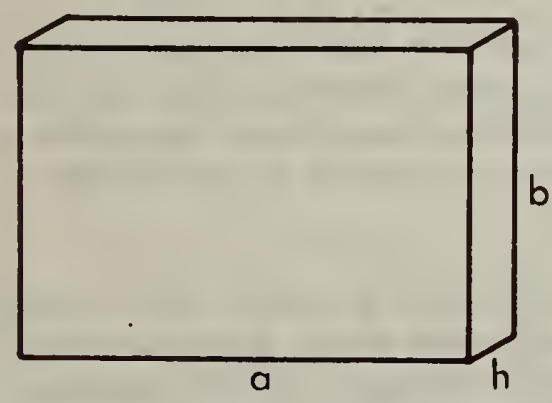

$m=$ Number of nodes along dimension $a$.

$\mathrm{n}=$ Number of nodes along dimension $\mathrm{b}$.

For fixed boundary conditions,

$\mathrm{m}=\mathrm{n}=2$ for lowest mode.

Figure 3. Sketch identifying dimensions of a vibrating plate.

For the fixed (or clamped) edge board, the frequency equation is

$$
f=\frac{1}{2 \pi}\left\{\frac{E g h^{2}}{12 \rho\left(1-\sigma^{2}\right)}\left[\frac{\gamma^{4}}{a^{4}}+\frac{\varepsilon^{4}}{b^{4}}+\frac{2 \gamma \varepsilon}{a^{2} b^{2}}(\gamma-2)(\varepsilon-2)\right]\right\}^{1 / 2} \text {, }
$$

where: 


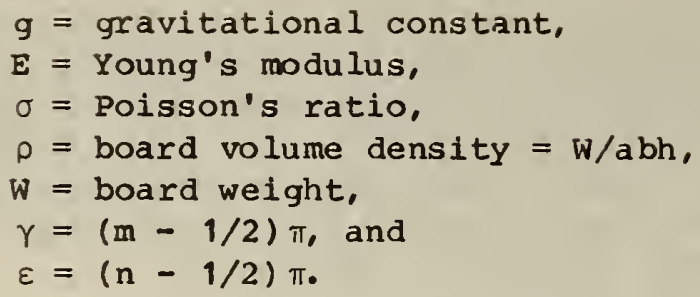

For the clamped board, the fundamental mode occurs for $m=n=2$ ( $a$ node at each end of the board).

For the supported PC board, the frequency equation is

$$
F=\frac{\pi}{2 a^{2}}\left\{\frac{E g h^{2}}{12 \rho\left(1-\sigma^{2}\right)}\left(\gamma_{1}{ }^{4}+\frac{a^{4}}{b^{4}} \varepsilon_{1}{ }^{4}+\frac{2 a^{2}}{b^{2}} \gamma_{1}{ }^{2} \varepsilon_{1}{ }^{2}\right)\right\}^{1 / 2},
$$

where $\gamma_{1}=m-1$ and $\varepsilon_{1}=n-1$.

The sketches in figure 4 give pictorial examples of the first several vibration modes of boards having various $a / b$ ratios. These were calculated for various boundary conditions as indicated.

To calculate the vibration modes ${ }^{*}$ to be expected in the first experiments (where boards that were fully copper clad on one side were used in the absence of etched ones), the following values for $E$ and $\varepsilon$ are composites of the appropriate thicknesses of epoxy board and copper cladding (all in English units) ${ }^{\dagger}$ :

$$
\begin{aligned}
& \mathrm{E}=2.8 \times 10^{6} \mathrm{psi}, \\
& \sigma=1.13, \text { and } \\
& \mathrm{g}=385 \mathrm{in} \cdot / \mathrm{s}^{2} .
\end{aligned}
$$

The dimensions of the board were $a=8.2 \mathrm{in.,} b=5.2 \mathrm{in} ., \mathrm{h}=0.062 \mathrm{in}$,, and $\mathrm{W}=0.21$ lbs. The dimensions were ones recommended for study by NAC ( 6 by 9 in.) reduced by the "fixed" clamp supports. The first several modal frequencies for fixed and supported edge boundary conditions are listed in table 1. For comparison, the last column in the table gives the model frequencies of a commonly used smaller board of the same thickness.

For comparison, if the constants appropriate to pure epoxy board (no copper cladding) ( $\mathrm{E}=2 \times 10^{6} \mathrm{psi}$ and $\sigma=0.12$ ) were used, the modal frequencies would all be approximately 16 percent lower. Although some of the frequencies in table 1 may appear to be rather high, these were included because

* A program for calculating eq (1) (fixed boundary conditions) appropriate to hand-held calculators using inverse polish notation is included in the appendix, since this is the boundary condition most used for PC boards in avionics equipment. A similar program for eq (2) is available on request to the author.

+ Dimensions and other values are generally given in English units since these are used exclusively in this field. 

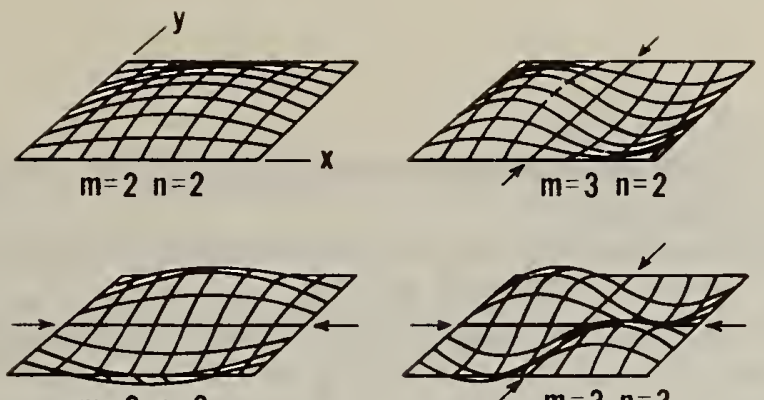

$m=2 n=3$

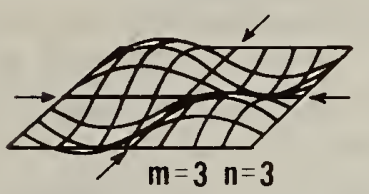

a. The first four vibration modes of a simply supported plate. (From Morse [17])

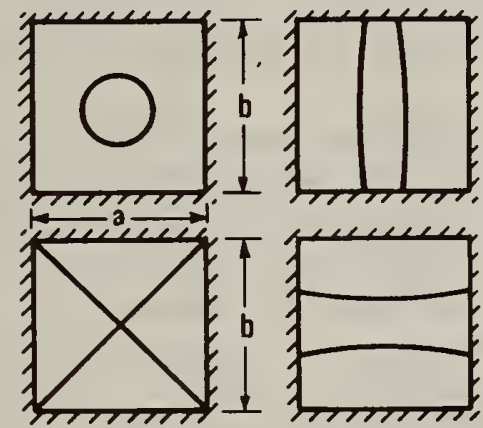

b. Vibration patterns of a square plate with fixed edges.
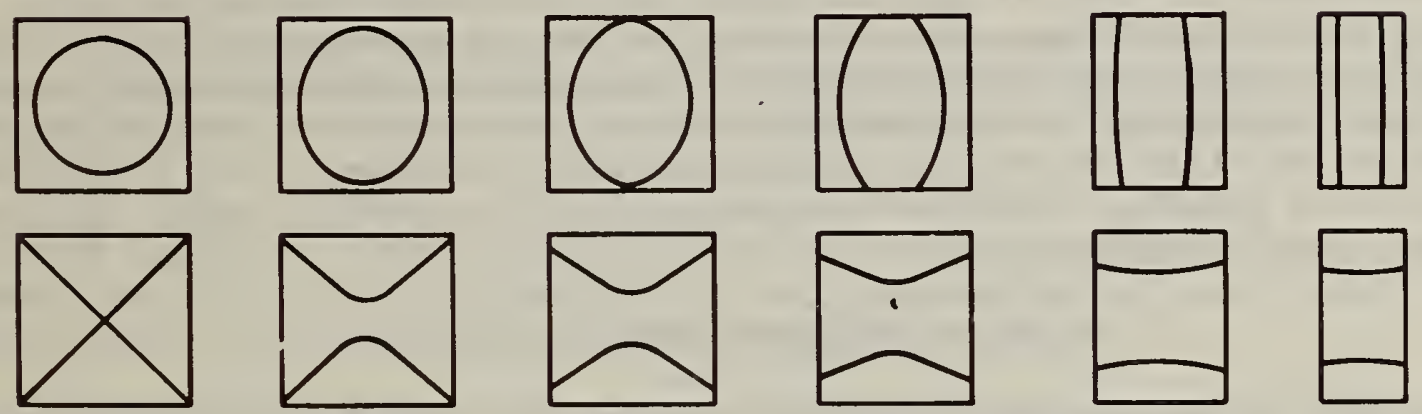

c. The variation of the vibration pattern as the length-to-width ratio changes on a plate having free edges.
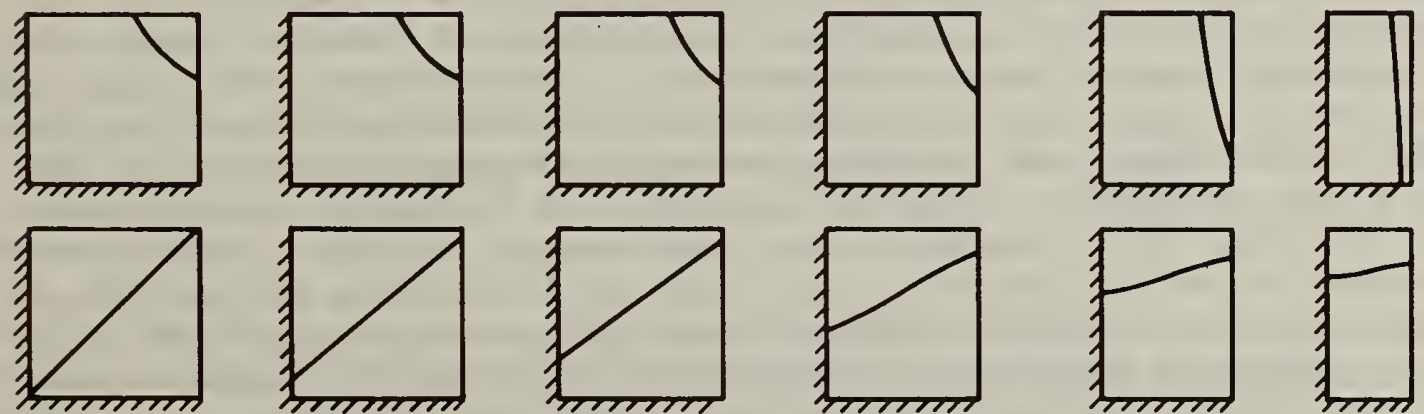

$a / b=1.00$

$a / b=0.98$

$a / b=0.95$
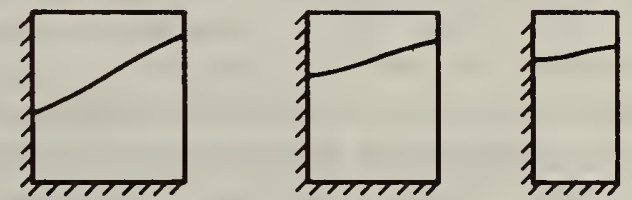

$a / b=0.90$

$\mathrm{a} / \mathrm{b}=\mathbf{0 . 7 5}$

$a / b=0.50$

d. The variation of the vibration patterns of a plate having two fixed and two free edges as the length-to-width ratio changes. These patterns also simulate the effect of nonuniform loading of a PC board. (From Warburton [18])

Figure 4. Pictorial examples of the first several vibration modes of rectangular boards. 
Table 1. Calculated Modal Frequencies for Two PC Boards.

\begin{tabular}{|c|c|c|c|c|}
\hline \multicolumn{2}{|c|}{ Modes } & \multicolumn{2}{|c|}{$\begin{array}{c}5.2 \times 8.2 \mathrm{in} . \\
(w=0.21)\end{array}$} & $\begin{array}{c}4 \times 6 \text { in. } \\
(w=0.118)\end{array}$ \\
\hline m & n & $f_{\text {fixed }}$ & $f_{\text {supp }}$ & $\mathrm{f}_{\text {fixed }}$ \\
\hline 2 & 2 & $330 \mathrm{~Hz}$ & $170 \mathrm{~Hz}$ & $570 \mathrm{~Hz}$ \\
\hline 3 & 2 & 495 & 320 & 885 \\
\hline 2 & 3 & 820 & 540 & 1400 \\
\hline 3 & 3 & 975 & 690 & 1685 \\
\hline 4 & 2 & 775 & 570 & 1410 \\
\hline 4 & 3 & 1235 & 935 & 2180 \\
\hline 4 & 4 & 1960 & 1550 & 3400 \\
\hline 3 & 4 & 1710 & 1300 & 2930 \\
\hline
\end{tabular}

they may be excited by harmonics of lower frequency vibrations entering an avionics box, as well as by "white" vibration transmitted from jet engines. Also, examination of eqs (1) and (2) shows that the modal frequencies of a uniformly loaded board decrease as the square root of the board's weight. Thus, since a board containing from 5 to 10 components (hybrids, capacitors, etc.) can easily weigh 2 to 4 times that of the unloaded board, the frequencies may be as little as one-half those calculated in table 1. It should be noted that all possible vibrational modes will not necessarily appear during actual PC board vibration.

\subsection{PC Board Layout Considerations}

Sketches such as those shown in figure 4 may be used by the PC board layout engineer to minimize vibrational damage to attached components. Obviously, it would be desirable to solder components at nodes; however, a node for one vibration mode could be a maximum for another. Higher order modes usually produce lower vibration amplitudes and, even though the frequency is higher (more excursions per second), result in less mechanical flexural damage to devices and their leads. Thus, only the four or five lowest order modes need to be considered. Component lead placement should avoid straddling the maximum of the lowest order mode, which is across the shortest dimension of the PC board. Thus, generally, component placement in the center of the board should be avoided. It is preferred that the devices straddle a node of higher order modes along the length of that node (while avoiding the maximum of the lowest mode). One should especially avoid placement in positions where leads will experience torsional forces since torsion can more easily damage the seal than linear flexing. The designer should also be aware that a board asymmetrically loaded with components (e.g., having the weight concentrated at one end) will not vibrate in the symmetrical manner shown in figure 4c, but may more nearly approach nodes shown in figure $4 \mathrm{~d}$. Thus, symmetrical loading is desirable, but if it is not possible, then various stiffeners or snubbers should be used $[10,15,22]$ as compensation. 


\subsection{Experimental Measurenents}

2.3.1 The Equipment Setup and Vibration of Unloaded PC Boards

After the literature and theoretical investigation was completed, an experimental program was begun. The complete experimental setup consisted of a programmable frequency driver; an Unholtz-Dickie* vibration shaker and control unit Model 106 SP7; two accelerometers, one for the shaker head and a 1-gram unit to be attached to the board or hybrid; a double-pen recorder to simultaneously record both the shaker and the board's acceleration, as well as a special synchronized strobe light to aid visual observation. A photograph of the overall experimental setup is given in figure 5 .

In consultation with NAC, it was determined that a "fixed" mount for the PC boards best simulated mounts found in the avionics equipment of interest. An appropriate mount was designed and constructed for use in vibrating boards along two major axes. Design considerations were obtained from the literature $[2,21,22]$ as well as from consultations with members of the NBS staff who have worked in the vibration field. A closeup of the mount, containing a PC board, four hybrids, and the 1-gram accelerometer, all attached to the shaker, is shown in figure 6. Swept sine frequency vibration tests revealed a mount resonance at approximately $900 \mathrm{~Hz}$. The control unit was progranmed to decrease the amplitude at that frequency. ${ }^{+}$

Several preliminary runs were made for calibration and equipment setup purposes. The equipment was progranmed to follow curves required in MIL-E-5400R, such as is shown in figure 7, curve IIIa, according to recomnendations of NAC.

Figure 8 gives the resonant frequency plot of a copper-clad PC board with dimensions of 8.2 by 5.2 by 0.062 in. The resonant peaks very closely resemble those calculated for the "fixed" board in table 1 .

Frequencies obtained from the chart, along with the appropriate nodes, are shown in table 2 .

Although the shaker drive was constant at $5 \mathrm{~g}$, the accelerometer on the board recorded troughs of $10 \mathrm{~g}$, which presumably resulted from overlapping resonances. Nevertheless, the board has an amplification factor (transmissibility) of $>10$ at some resonances. It is apparent from table 2 that modes through $m=3, n=3$ produce excellent agreement with theory. However, higher order modes do not agree as well. Presumably, this results from slight material inhomogeneities in the board and/or slight variations from a true "fixed" mount.

* Use of this equipment does not constitute endorsement of that product. This particular equipment was used because it was readily available.

+ After the initial tests (and the period covered by this report), the mount was modified and the driver power supply replaced in order to minimize this resonance, so that it will not be a significant factor in future tests. 


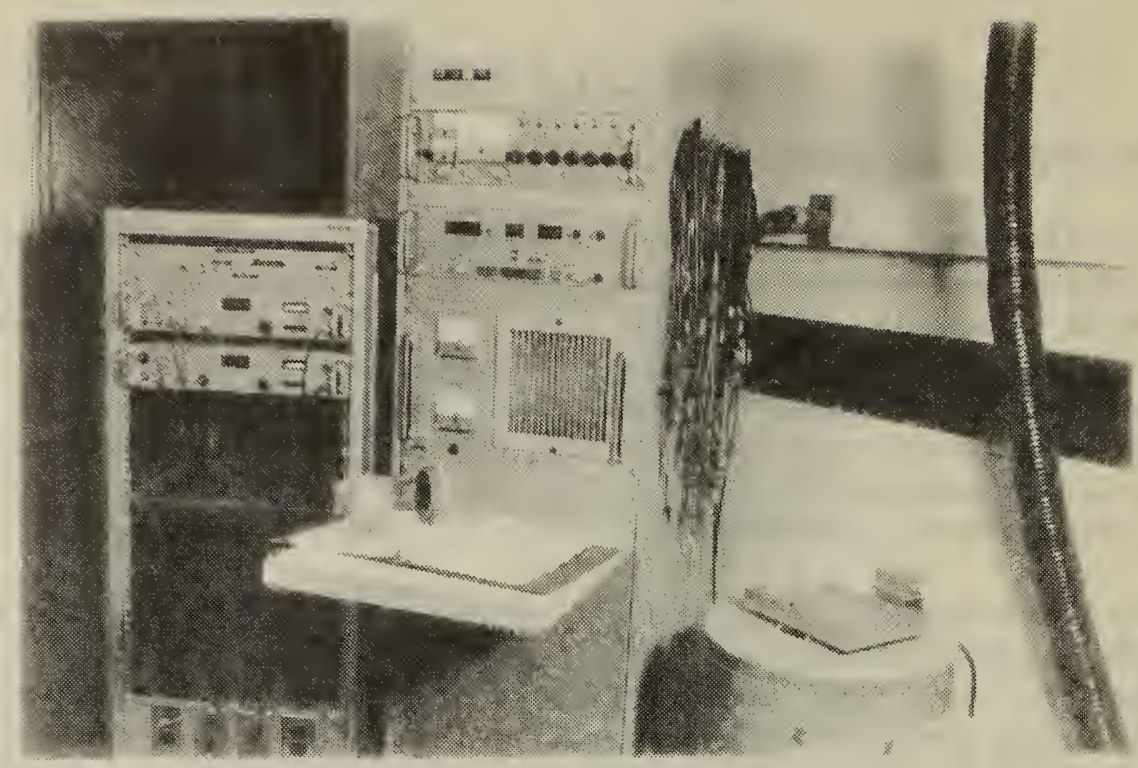

Figure 5. An overview of the vibration equipment.
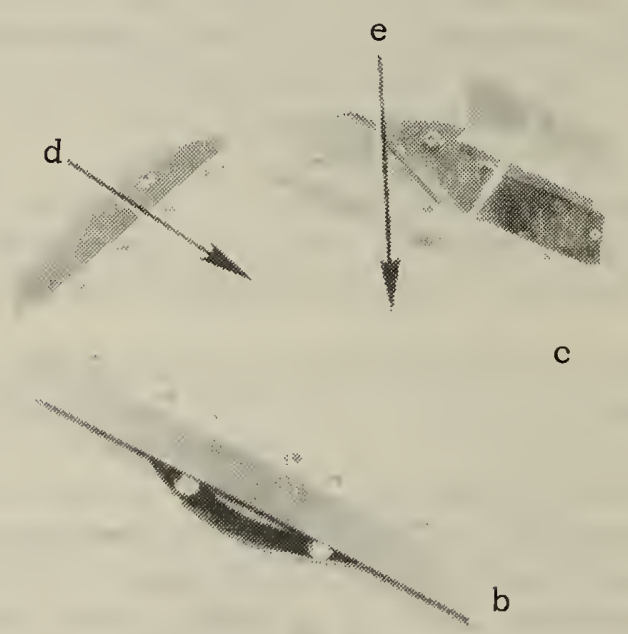

a

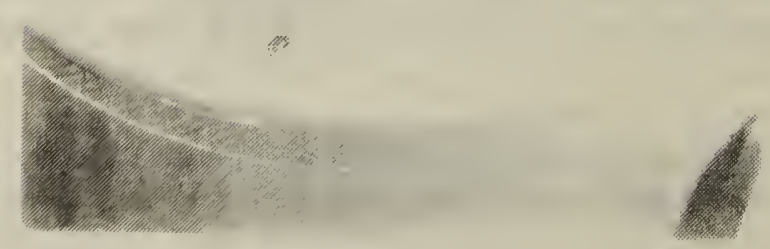

Figure 5. A closeup of the vibration shaker unit (a), showing the PC board "fixed" mount (b), and a PC board (c) with four hybrids on it (d). A 1-gram accelerometer (e) is attached to one hybrid. 


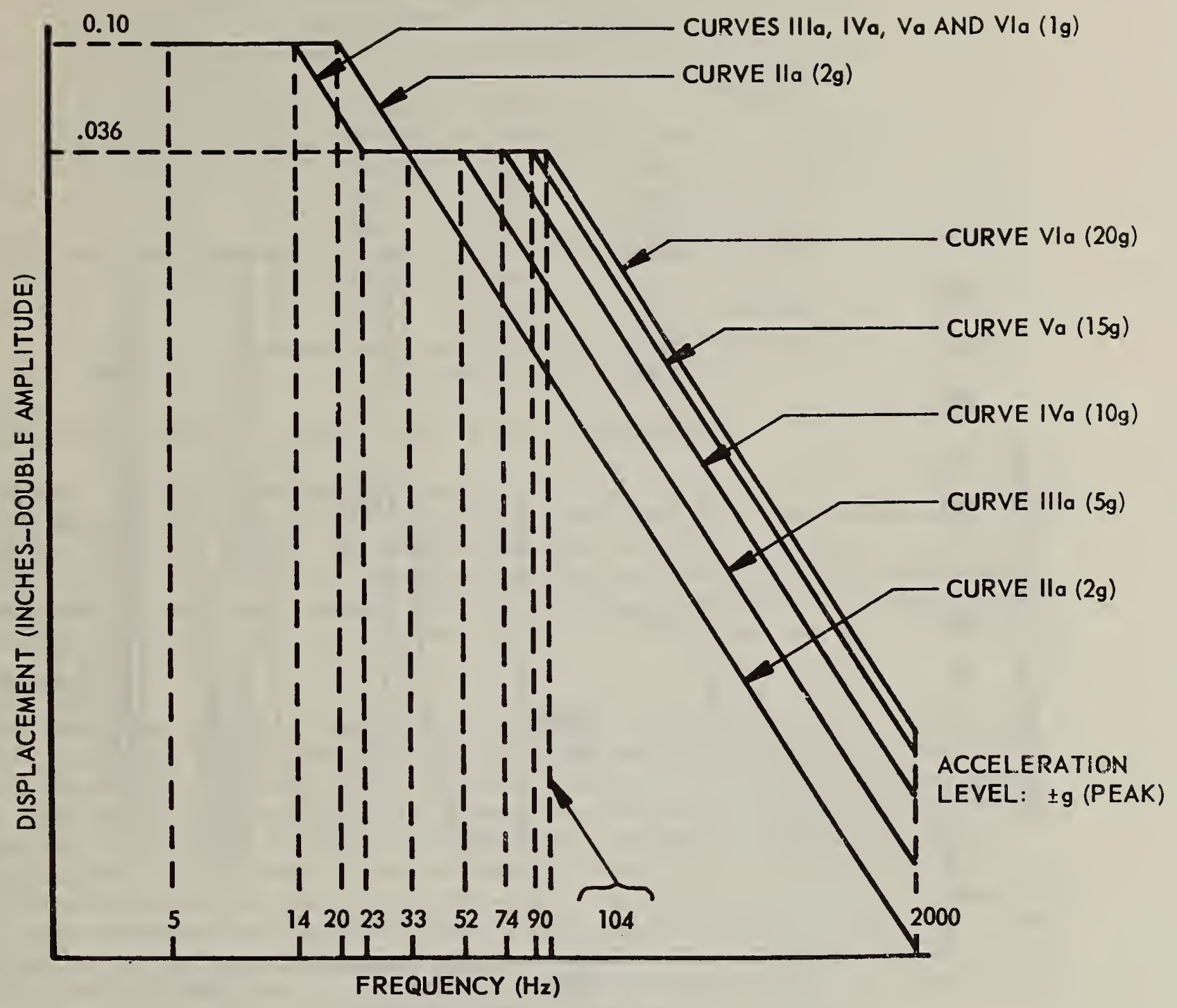

CURVE la (OF PREVIOUS ISSUES) - REPLACED BY CURVE IVa

CURVE IIa - EQUIPMENT DESIGNED FOR OPERATION ON ISOLATORS WITH ISOLATORS REMOVED

CURVE $I 110$ - EQUIPMENT MOUNTED IN FORWARD HALF OF FUSELAGE OR IN WING AREA WITH ENGINES AT REAR OF FUSELAGE

CURVE IVa - EQUIPMENT MOUNTED IN REAR HALF OF FUSELAGE OR IN WING AREA WITH WING OR FRONT MOUNTED ENGINES

CURVE Va - EQUIPMENT MOUNTED IN ENGINE COMPARTMENT OR ENGINE PYLON CURVE VIa - EQUIPMENT MOUNTED DIRECTLY ON ENGINE

Figure 7. The sinusoidal vibration requirements for equipment designed for installation in jet airplanes (from MIL-E-5400R). 


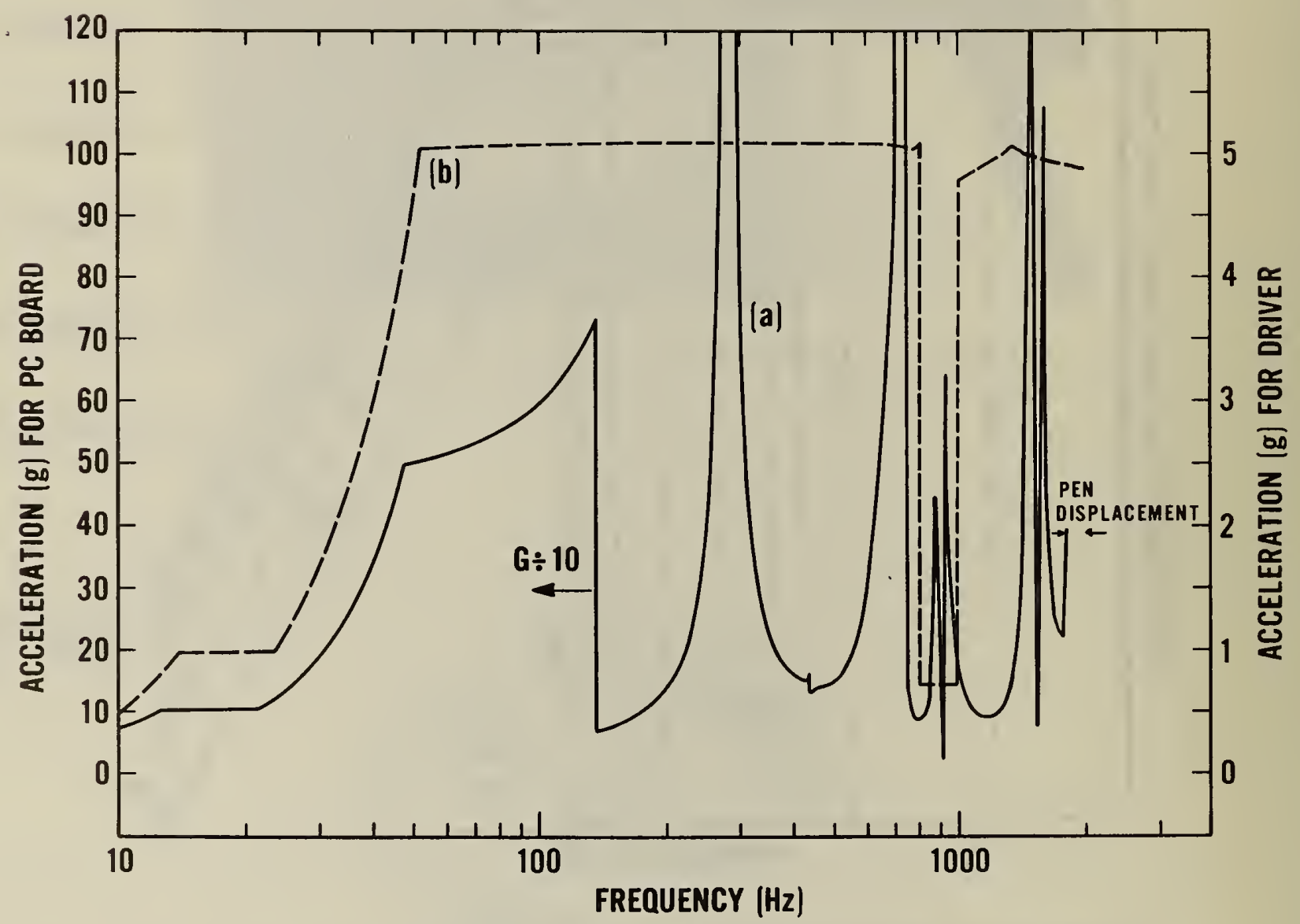

Figure 8. The resonant vibration peaks on a 20 -min frequency sweep of a PC board (curve a). The recorder pen was displaced $1 / 8-i n$. to the left to prevent intercepting the calibrating pen that was recording the shaker drive (curve b). Saturation on the resonances is evident on three peaks. 
Table 2. Comparison Between Calculated and Measured Modal Frequencies.

\begin{tabular}{lllll}
\hline \multicolumn{2}{c}{ Modes } & $\mathbf{f}_{\text {meas }}$ & $\mathbf{f}_{\text {calc }}$ & \multicolumn{1}{c}{ Comments } \\
\hline 2 & $\mathrm{n}$ & $310 \mathrm{~Hz}$ & $330 \mathrm{~Hz}$ & Peak $>100 \mathrm{~g}$ \\
3 & 2 & 480 & 495 & Very small peak \\
2 & 3 & 800 & 820 & Peak $>100 \mathrm{~g}$ \\
3 & 3 & 960 & 975 & Peak $\approx 80 \mathrm{~g}$ \\
5 & 2 & 1020 & 1160 & Peak $>100 \mathrm{~g}$ \\
5 & 3 & 1640 & 1603 & Peak near 100 g \\
3 & 4 & 1760 & 1710 & Peak $>100 \mathrm{~g}$ \\
\hline
\end{tabular}

\subsubsection{Vibration of PC Board-Mounted Hybrid Packages}

In order to prepare butterfly-type hybrid packages for mounting on boards, it was necessary to bend and cut the leads. NAC indicated that they bent them $0.05 \mathrm{in}$. from the seals. Package manufacturers do not recommend bending leads closer than $0.10 \mathrm{in}$. from the package and prefer a 0.15-in. spacing. * Subsequently, two lead bending-cutting jigs were designed and constructed. One bent the leads $0.07 \mathrm{in}$. and the other $0.15 \mathrm{in}$. from the edge of the package.

Eight packages had their leads bent and cut, four on each jig. All showed a small degree of glass damage to two or three out of 30 leads, but this was much less than on NAC-supplied pre-bent samples. Two of the best packages, one with short and one with long leads, were soldered to unetched PC boards. This was facilitated by scribing a moat with a sharp knife in the copper cladding around the area to be soldered. The thermal conductivity away from the leads was thereby decreased and soldering with a small iron was possible. The open packages were mounted side by side in the center of the board with the leads in the short direction of the board. This was intended to be the worse position for damage by excitation at the lowest mode. A 1-gram accelerometer was attached to the package with the shorter lead spacing.

The "fixed" nature of the board mount was verified by observation under the strobe light with lycopodium powder placed on the board during a preliminary run. Resonant amplitude peaks were measured both with the accelerometer and with a depth gage micrometer from a fixed nonresonant portion of the mount. The lowest resonant mode of the board with soldered-in hybrids was $280 \mathrm{~Hz}$ which compares well with the calculated value of $308 \mathrm{~Hz}$ if the addition of $0.03 \mathrm{lbs}$. to the board's weight by the packages, solder, and accelerometer is taken into account. Had this weight been more evenly distributed, presumably the two frequencies would have been even closer.

The object of this test was to vibrate the PC board sufficiently to damage seals, to observe the relative damage resulting from the two different lead lengths, and to use the information to set up an even more controlled test

* Dan Zimmerman, Johns Hopkins Applied Physics Labs, private communication. 
using an acoustic emission detector to observe glass-metal seal damage as it occurs.

During the test, several frequency sweeps were made from $10 \mathrm{~Hz}$ to $2 \mathrm{kHz}$; however, the programmed rate of frequency change was varied to allow longer observation with the strobe at the resonances and to make amplitude measurements. At several resonances, clear differential motion was observed between the packages, with the greatest motion occurring on the one having the longest leads. At one point, package rotation was observed, and at higher modes differential motion from one side of the package to the other was observed. After the third frequency sweep, different vibration noises were heard. It was concluded that some lead damage had been sustained, and the test was concluded. The damage was extensive both to the leads, by fatigue, and to the: glass seals as observed under a microscope. Eighty percent of the leads on the package with longer lead spacing were damaged or broken, as is evident in the photomicrograph in. figure 9. No leads were broken in the package with shorter leads, but some glass cracking was observed.

The packages were then removed from the board for further observation of the damage and evaluation by a newly developed high-temperature leak test method, which is described in section 4 of this report. The room temperature leak test showed both packages to have leak sizes less than $10^{-8} \mathrm{~atm} \cdot \mathrm{cm}^{3} / \mathrm{s}$ helium. Tests at $125^{\circ} \mathrm{C}$ gave similar results, leak sizes less than $5 \mathrm{x}$ $10^{-8} \mathrm{~atm} \cdot \mathrm{cm}^{3} / \mathrm{s}$ helium, the test limit. The packages were put on a thermoelectric temperature cycling system and cycled 25 times from $-55^{\circ}$ to $125^{\circ} \mathrm{C}$ with a $7-\min$ cycle time. They were retested, and again the package with shorter leads had a leak size less than $10^{-8} \mathrm{~atm} \cdot \mathrm{cm}^{3} / \mathrm{s}$ helium at room temperature and $5 \times 10^{-8} \mathrm{~atm} \cdot \mathrm{cm}^{3} / \mathrm{s}$ helium at $125^{\circ} \mathrm{C}$. However, the package with the longer leads, which had sustained considerable damage, showed a $10^{-7} \mathrm{~atm} \cdot \mathrm{cm}^{3} / \mathrm{s}$ helium leak at one lead at room temperature and $10^{-7} \mathrm{~atm} \cdot \mathrm{cm}^{3} / \mathrm{s}$ helium leaks at two leads (one was the room temperature leak) at $125^{\circ} \mathrm{C}$. It should be noted, however, that a $10^{-7}$ leak is acceptable in Method 1014.2 of MIL-STD-883, Test Methods and Procedures for Microelectronics, for packages of volume $2 \mathrm{~cm}^{3}$ or greater. Thus, the packages cannot be considered to have failed hermetic tests even though several leads had been fatigued of $f$.

Plans to run an acoustic emission test simultaneously with vibration testing were postponed until etched boards have been received from NAC. However, a special acoustic emission detector was developed to be more sensitive to surface waves and less sensitive to vibration-induced cable noise, since noise had been observed in experimental runs. This detector is described in section 3. Test procedures and $A E$ waveform signatures to separate $A E$ due to lead fatigue from that due to glass cracking are yet to be developed. It is difficult to base any recommendations on the preliminary vibration experiments described above. Certainly, the theory has been demonstrated to correlate well with experiment, and some general guidelines for PC board layout to minimize vibration damage were given. It is apparent that considerable glass-seal damage does not necessarily result in leaks of sufficient size to require rejection of hybrid packages either at room or high temperature. However, packages from this same lot had been shock tested from $400^{\circ} \mathrm{C}$ to liquid nitrogen and also passed the leak test, indicating that these packages were of very high quality. Packages with flaws in the kovar, glass, or 


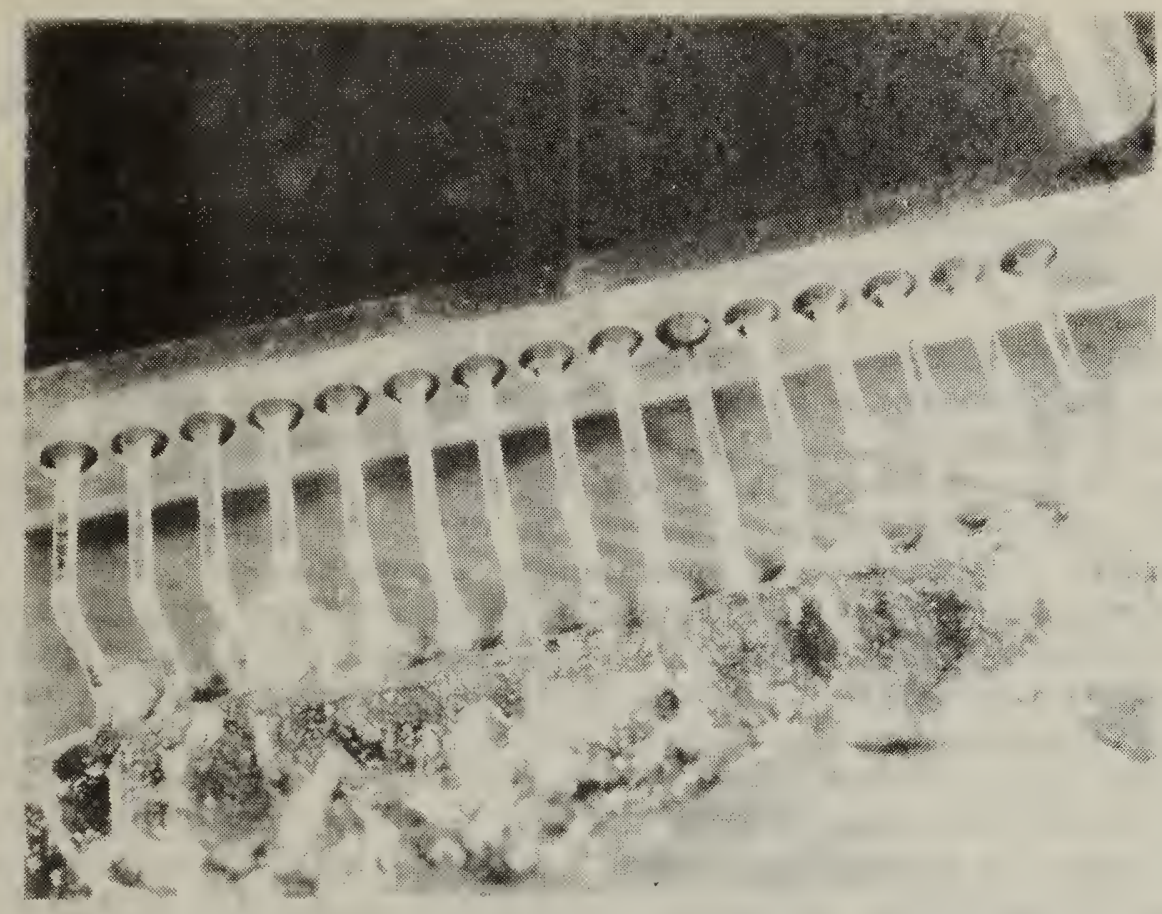

\section{(a)}

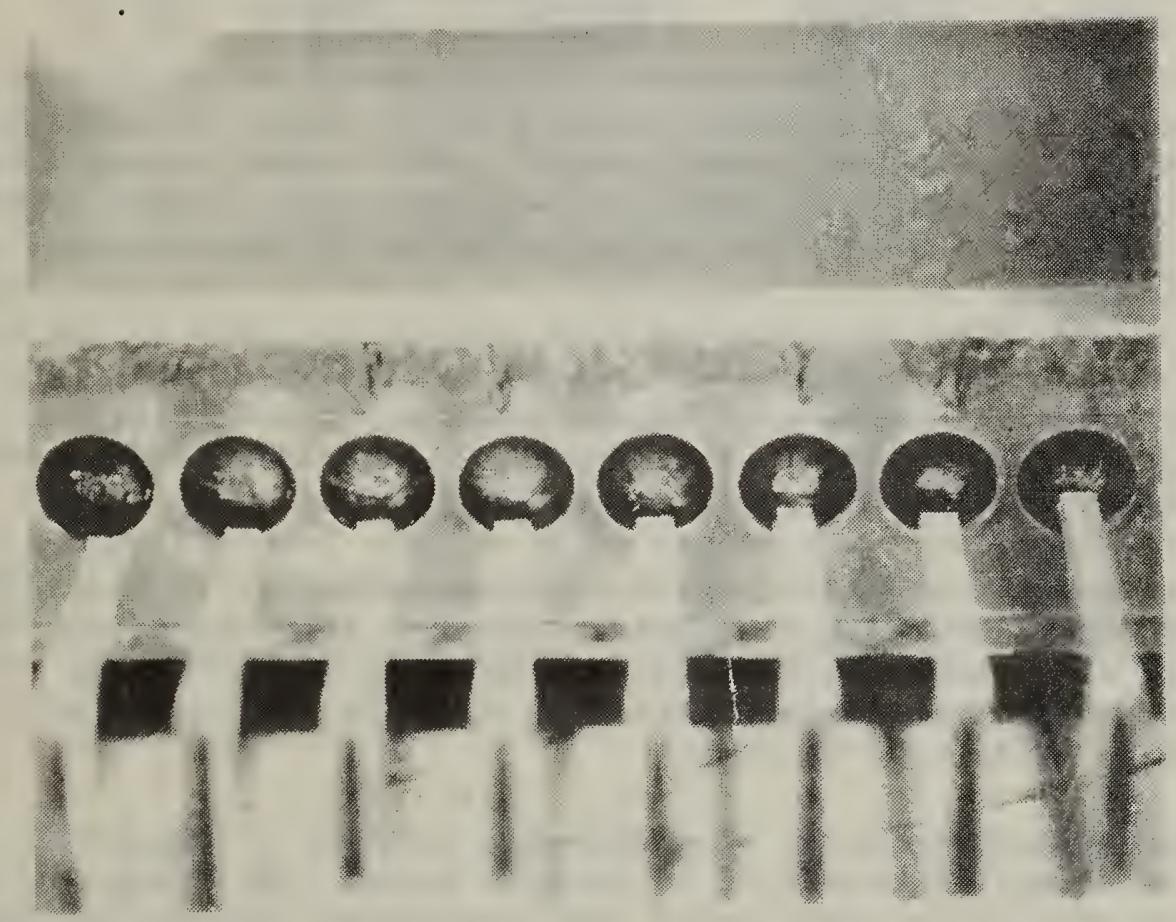

(b)

Figure 9. Photomicrographs of a 1-in. square hybrid package after vibration testing. (a) Leads fatigued off during vibration tests at the package seals, showing glass damage. (b) Leads fatigued off at the bends or at the solder joints. 
oxdde might react quite differently under vibration conditions; study of such packages would be part of a continuing investigation.

\section{DEVELOPMENT OF AN ACOUSTIC EMISSION DETECTOR RESISTANT TO VIBRATION-INDUCED CABLE NOISE AND SENSITIVE TO SURFACE WAVES}

Acoustic emission sensors are usually designed to have the PZT element recessed into the case and a plastic element extending to the surface for acoustic wave coupling. They are also typically designed to have maximum sensitivity in the direction of the thickness of the PZT disc. Thus, maximum sensitivity occurs for waves entering the detector normal to its surface rather than for a surface wave propagating along the base or top of a hybrid package. Acoustical wedges have been used to increase the sensitivity of AE sensors to surface waves. However, a disc-shaped PZT sensor lying flat on the surface is sensitive to surface waves propagating along its diameter, and the resonant frequency of the sensor for these waves is determined by the diameter rather than the thickness of the sensor. Also, the impedance of $\mathrm{AE}$ sensors is relatively high ( 10 to $20 \mathrm{k} \Omega$ ), and the output for weak signals is low in the order of microvolts. Some of this signal is lost due to cable capacitance; in addition, shielded cable noise generated during PC board vibration tests limits the maximum sensitivity of the detectors. In order to complete all objectives of the NAC program, it was necessary to develop an improved sensor to overcome the above limitations.

A detector meeting the requirements outlined above was constructed as follows: sensors with a diameter of about $0.25 \mathrm{in}$. were ultrasonically cut from larger diameter, 1-MHz PZT ceramic stock. PTFE-coated copper wires 0.003 in. in diameter were soldered to the silver-coated faces of the ceramic disc, and the element was bonded into the cap of a TO-100 IC package which had a thin layer of polyimide in it as insulation. A $\mu \mathrm{A}-733$ differential input-output operational amplifier was attached with insulating epoxy to the base of the TO-100 package and wire bonded so that it had a gain of 100 . The chip was protected with a thin film of xylene-thinned silicone rubber, and the wires were protected from shorting by a film of photoresist. Photographs of the basic assembly steps are given in figure 10 .

The completed detector-amplifiers weigh approximately 1.3 grans and, therefore, offer negligible damping when attached to hybrids undergoing vibration tests. All connections to the device, including signal leads, are unshielded twisted pairs in which vibration-induced noise is negligible at the low output impedance of the $\mu \mathrm{A}-733$ chip.

The frequency response curve of a detector is given in figure 11. The 350$\mathrm{kHz}$ peak is primarily sensitive to surface waves. The frequency response was obtained by driving the test units with a smoothed response calibrated transducer. The absolute response was not measured, but the response data supplied by the manufacturer is plotted and the relative correction is apparent. When the TO-100 detector was attached to a package and tested for simulated continuous-signal surface wave response, the unit was 5 to $10 \mathrm{~dB}$ more sensitive (signal-to-noise ratio) than standard $\mathrm{AE}$ detectors with the same frequency range. Absolute calibrations of the detectors for their sensitivity to AE-type surface waves will be made elsewhere in NBS at a later time. A sensor of the type described is desirable in all tests involving $\mathrm{AE}$ detection 


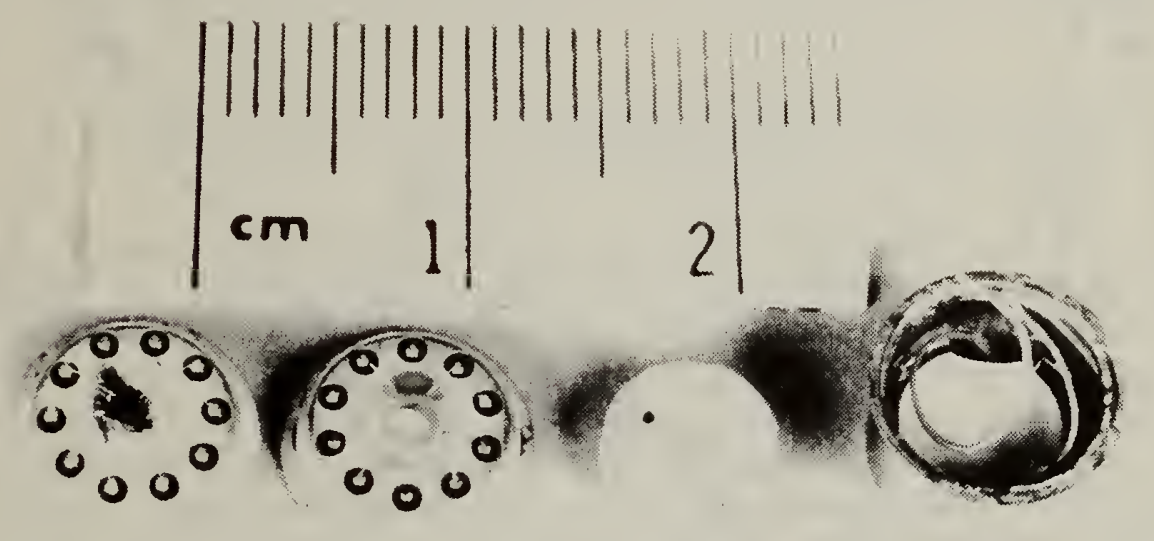

Figure 10. Steps in the assembly of the TO-100 acoustic emission detector amplifier. From left to right, the $\mu A-733$ chip is die bonded and wire bonded; then a silicone junction coating material is applied. Next, a PZT AE detector chip is shown. On the right it has leads attached and is held to the TO-100 cap with a polyimide adhesive. The leads are then ultrasonically attached to the package, the cap is welded on, and external power and signal leads are attached. (A closeup of a finished detector is shown in fig. 17.) 


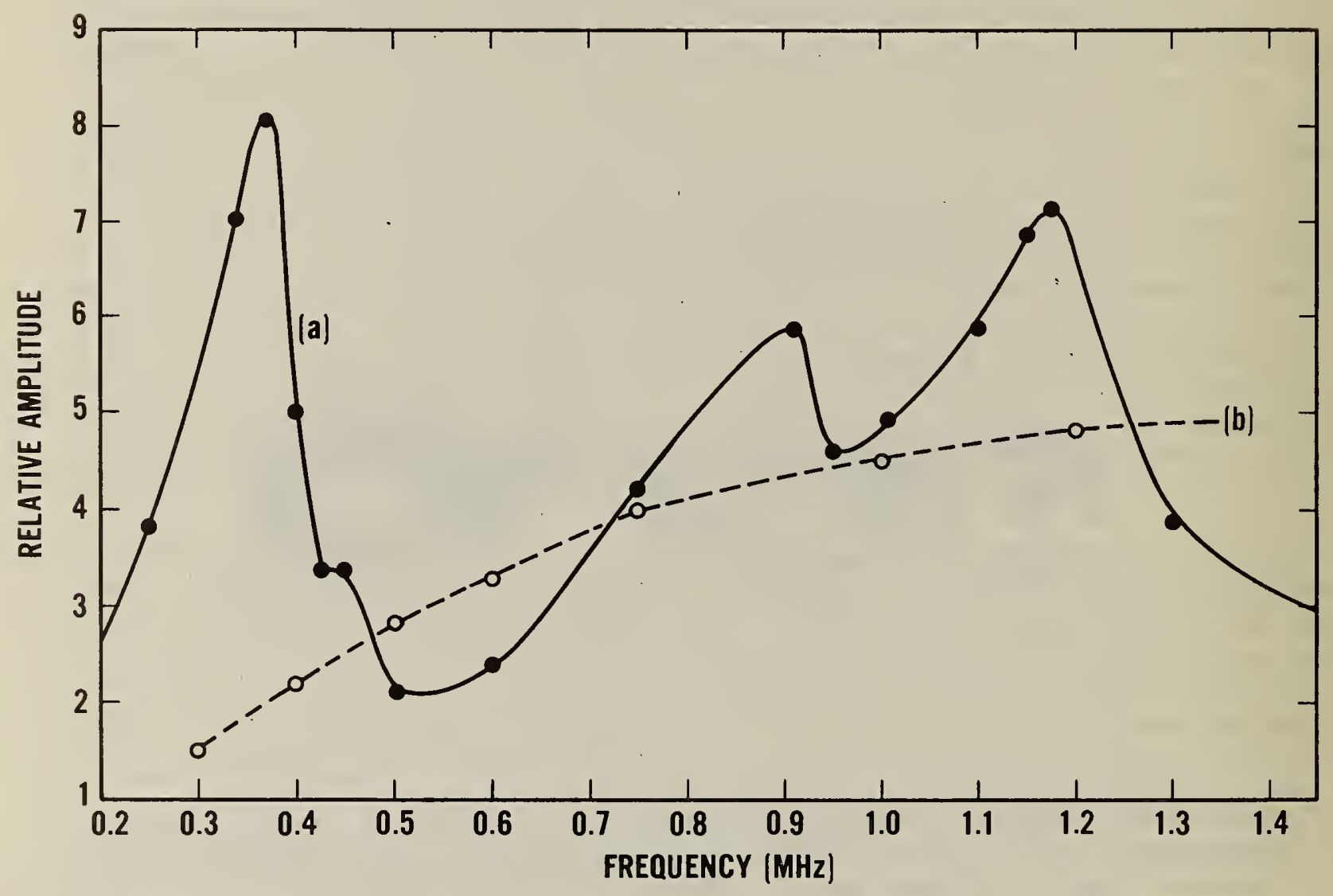

Figure 11. Frequency response curve of a PZT AE detector. (a) The continuous excitation relative response curve of a TO-100 AE detector. (b) The relative calibration of the driving transducer. The PZT transducer is designed to operate in the thickness direction where its response is maximum, at about 1.1 $\mathrm{MHz}$. The diameter direction response is approximately $350 \mathrm{kHz}$. 
of signals emitted during package tests, since thin package lids can only transmit surface waves.

In use, these TO-100 detectors are attached to the hybrid package with various standard AE couplants, as well as water. The detectors are held in place with assorted clamps, jigs, or weights. However, it was necessary to determine the optimum material that would serve both as an $A E$ couplant and a mechanical glue-like attachment for use in holding the detectors during vibration tests. Several thermoplastic materials typically used as AE couplants were rejected because of their brittleness, since any cracks that developed in the couplant during a vibration test could generate acoustic emission which might be confused with signals emitted from cracking seals. A series of tests involving a dozen different materials determined that beeswax would adequately serve as both mechanical and $A E$ couplant for vibrational purposes. The TO-100 detector can be attached either by melting the beeswax $\left(270^{\circ} \mathrm{C}\right)$ or by solvent evaporation.

\section{DEVELOPMENT OF A HIGH-TEMPERATURE OPEN-PACKAGE LEAK TEST PROCEDURE}

It has been reported by Thomas [25] that some packages leak at high temperatures $\left(\sim 125^{\circ} \mathrm{C}\right)$ or during rapidly changing temperatures, such as encountered in shock tests, but are well sealed during normal room temperature leak tests. There are two reasons for this. The first is that the kovar-glass seal is in tension at $125^{\circ} \mathrm{C}$, but in compression at room temperature [26] . Thus, if there are cracks, they may open and result in leaks at $125^{\circ} \mathrm{C}$, but reseal at lower temperatures. The second reason is that, during rapid temperature rise, nonequilibrium conditions exist with the glass temperature lagging that of the better conducting kovar, putting any weak areas of the seal in significant tension, thus causing cracks. Therefore, in order to fully evaluate seal damage and correlate this with acoustic emission bursts, it was necessary to develop a high-temperature open-package leak test.

The normal open-package leak test, using neoprene rubber and a standard vacuum grease, is not useful at $125^{\circ} \mathrm{C}$ because the rubber becomes highly permeable to helium and the grease becomes mobile and moves out from under the package edges.

The first efforts to develop a high-temperature leak test were directed towards finding published data on the permeation of helium through various elastomers and greases at temperatures greater than $100^{\circ} \mathrm{C}$. No such information was available. The next step was to obtain several different greases and very thin sections of different elastomers and greases and leak testing known good packages at various temperatures, choosing the best combination. combination. The present system uses Viton $A^{*}$ elastomer and Fomblin* grease. This combination is adequate for leak testing to $10^{-7} \mathrm{~atm} \cdot \mathrm{cm}^{3} / \mathrm{s}$.

* Certain commercial equipment, instruments, or materials are identified in this paper in order to adequately specify the experimental procedure. In no case does such identification imply endorsement by the National Bureau of standards, nor does it imply that the material or equipment identified is necessarily the best available for the purpose. 
A temperature-controlled package heater was designed and constructed. It is shown in figure 12 .

Although a number of packages have been successfully tested by this method, new procedures and materials will be investigated in the future.

\section{DEVELOPMENT OF AN AE-MONITORED THERMAL SHOCK TEST*}

McCormick and Zakraysek [27] described the effect of kovar oxide thickness on the reliability of the glass-metal seal. They concluded that a shock test (MIL-STD-883 Method 1011.2 Condition C) was an adequate test for packages. However, inquiry revealed that many manufacturers routinely use a hot stage shock test unless the MIL-STD-883 test is specifically called out. Briefly, the hot stage test is performed as follows: a kovar flat-pack containing glass-to-metal seals is placed on a surface (hot stage) heated to a temperature usually in the range of $350^{\circ}$ to $400^{\circ} \mathrm{C}$. The package is allowed to reach equilibrium. Following removal and cooling, the glass seals are examined or tested for damage. Because of the frequent use of the shock tests as a screen, it would be desirable to instrument this test with $\mathrm{AE}$-detection equipment. Such a test could also be used as a shock test at lower temperatures $\left(\sim 150^{\circ} \mathrm{C}\right)$ for hybrid component bond integrity as well as to reveal substrate cracks.

The high temperatures of the hot stage required for this test presented dual problems for $\mathrm{AE}$ detectors. Rapid heating can produce extraneous AE-like noise, and the most sensitive detectors have Curie point restrictions and/or mount constructional materials (i.e., epoxy) that can be damaged by the high temperatures. The first experiments to protect the detector used a stand-off acoustical waveguide made of Pyrex attached to an AE detector, the unattached end being coupled to the hot package. The detection efficiency of this method was very low because no acoustical couplant (for use between package and waveguide) could be found that would withstand package temperatures of $350^{\circ}$ to $400^{\circ} \mathrm{C}$. Also, this waveguide extension had very low sensitivity to surface waves.

Next, a small water-cooled detector mount was designed and constructed. This adequately stabilized the detector temperature when the package was turned face down and some thin insulation material, such as fiberglass or ceramic, was interposed as a radiation-convection barrier inside the package between the hot plate and the package lid. A photograph of the cooled detector mount, hybrid package, and hot stage is shown in figure 13.

Additional tests were made with a small thermocouple attached on the inside bottom of the package, directly under the detector. With the package walls in equilibrium ( $>1 \mathrm{~min}$ on $\mathrm{a} 400^{\circ} \mathrm{C}$ hot stage), the detector temperature cycled (in synchronization with the hot stage cycling) from $50^{\circ}$ to $54^{\circ} \mathrm{C}$. With maximum possible water flow through the cooler, the detector cycled between $42^{\circ}$ and $45^{\circ} \mathrm{C}$. Either temperature range is satisfactory and does not lead to spurious $A E$ signals. The $A E$ apparatus has been tested; small induced cracks in the glass seals have been detected with the package at $400^{\circ} \mathrm{C}$. No packages with appropriately weak seals were available during the period of this con-

* Most of the work in this section was carried out after september 30, 1979 and thus was not sponsored by NAC, but is included for completeness. 


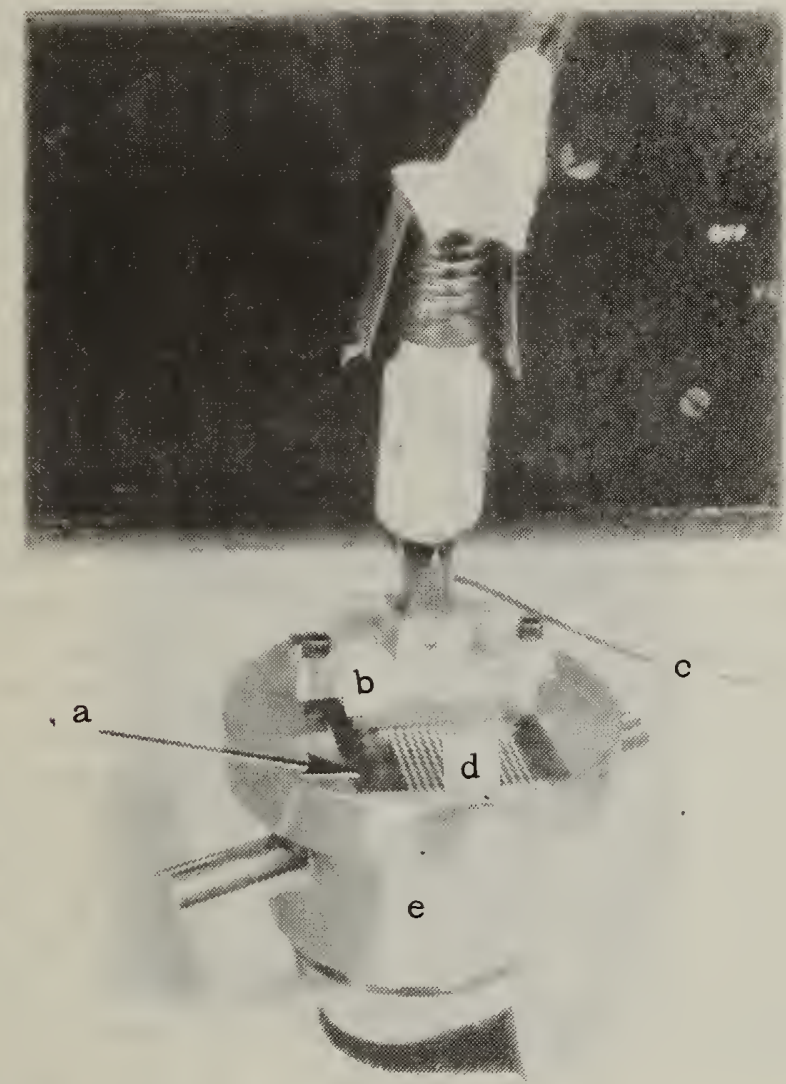

Figure 12. The high-temperature open package leak test apparatus. (a) Fluorocarbon elastomer gasket. (b) Platen used to conduct heat uniformly to the package. A thermocouple controls the temperature on the platen. (c) Heater element. (d) Hybrid package. (e) Leak detector port. 


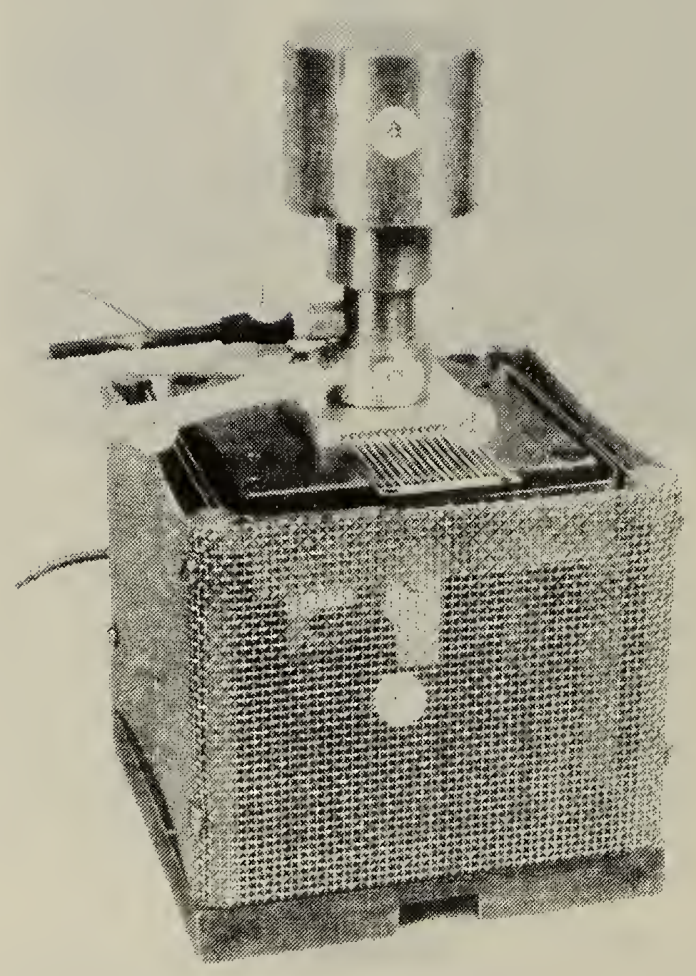

Figure 13. Thermal shock hot stage with a hybrid package and a water-cooled $\mathrm{AE}$ detector on top. (a) Brass weight to hold the spring-loaded detector against the package. (b) Part of the lead and connector from the AE detector. (c) Water-cooling jacket around the AE detector. (d) Hybrid package shown face down on the hot stage. (e) Silicone rubber coolant tubing. (f) Hot stage surrounded by a protective screen. 
tract for use in screening tests. However, arrangements have been made with a hybrid facility to obtain a number of their rejects, and these are expected early in the next fiscal year.

Since the face-down package configuration is different from the usual face-up hot stage test, it was necessary to carefully measure the thermal character-

istics for both situations. It became evident that this frequently used test is not well characterized, and under various conditions, it should be possible to pass weak products because the temperature rise can be too slow to adequately stress package seals.

The experimental arrangement is the same as was shown in figure 13, except that $0.003-i n$. diameter thermocouple wires were welded to the inside wall of the package at the same level as the lead-throughs. In order to be sure the actual wall temperature was monitored, the thermocouple was split and each wire welded separately, approximately $0.01 \mathrm{in}$, apart, to the package wall. Data were taken at 5-s intervals using a digital read-out thermometer. The first few runs gave poor reproducibility, so the hot plate surface was flattened and smoothed with a fine file. The package bottom was also lightly polished. Figure 14, curve (a), gives the average temperature-time curve of a package, bottom-down (the normal configuration), on the $400^{\circ} \mathrm{C}$ hot stage for a gold-plated package of $1-1 / 4$ by 2 by 0.3 in. dimensions. Each point is the average of three runs. For comparison, curve (c) was taken under conditions identical to (a) except that two short pieces of 0.003-in. diameter alumel thermocouple wire were placed on the hot stage under one edge of the package. The wire was invisible except when viewed in oblique light. Curve (d) is taken similar to (c) except a $0.05-i n$. Iong by $0.015-$ by $0.010-i n$. piece of kovar from a package lead was placed underneath and near one end of the package. The 0.015-in. dimension was horizontal. From examination of the curves, it is apparent that the initial temperature rise at the glass seal can vary considerably, and much care should be exercised in carrying out the test. Factors leading to varying temperature rise conditions are: package design (i.e., height of seals above bottom surface) and size of package, plating and reflectivity, particles or other contaminants or irregularities on the surface of the hot stage, and possible drafts across its surface. Liquid immersion to a lower peak temperature would certainly be more reproducible and presumably just as effective, considering the maximum stress temperatures of the kovar glass seal [26].

After characterizing the normal hot stage thermal shock test, it was necessary to obtain equivalent data on the package face-down with convection and radiation shields and a cooled detector on the bottom. After several runs, it was determined that the equivalent rate of temperature rise in the important initial $20^{\circ}$ to $200^{\circ} \mathrm{C}$ range was obtained with the stage temperature increased $\sim 25^{\circ}$ to $425^{\circ} \mathrm{C}$, as shown in figure 14 , curve (b).

Only a single hot stage and two package types have been characterized in these tests. Different organizations may use quite different stages, ranging from small substrate heaters to large hot plates, as well as a large variety of package types. Therefore, the hot stage thermal shock test probably cannot be standardized. Nevertheless, each particular setup should be characterized, and the surface of the stage smoothed and kept clean in order to obtain self-consistent results. 


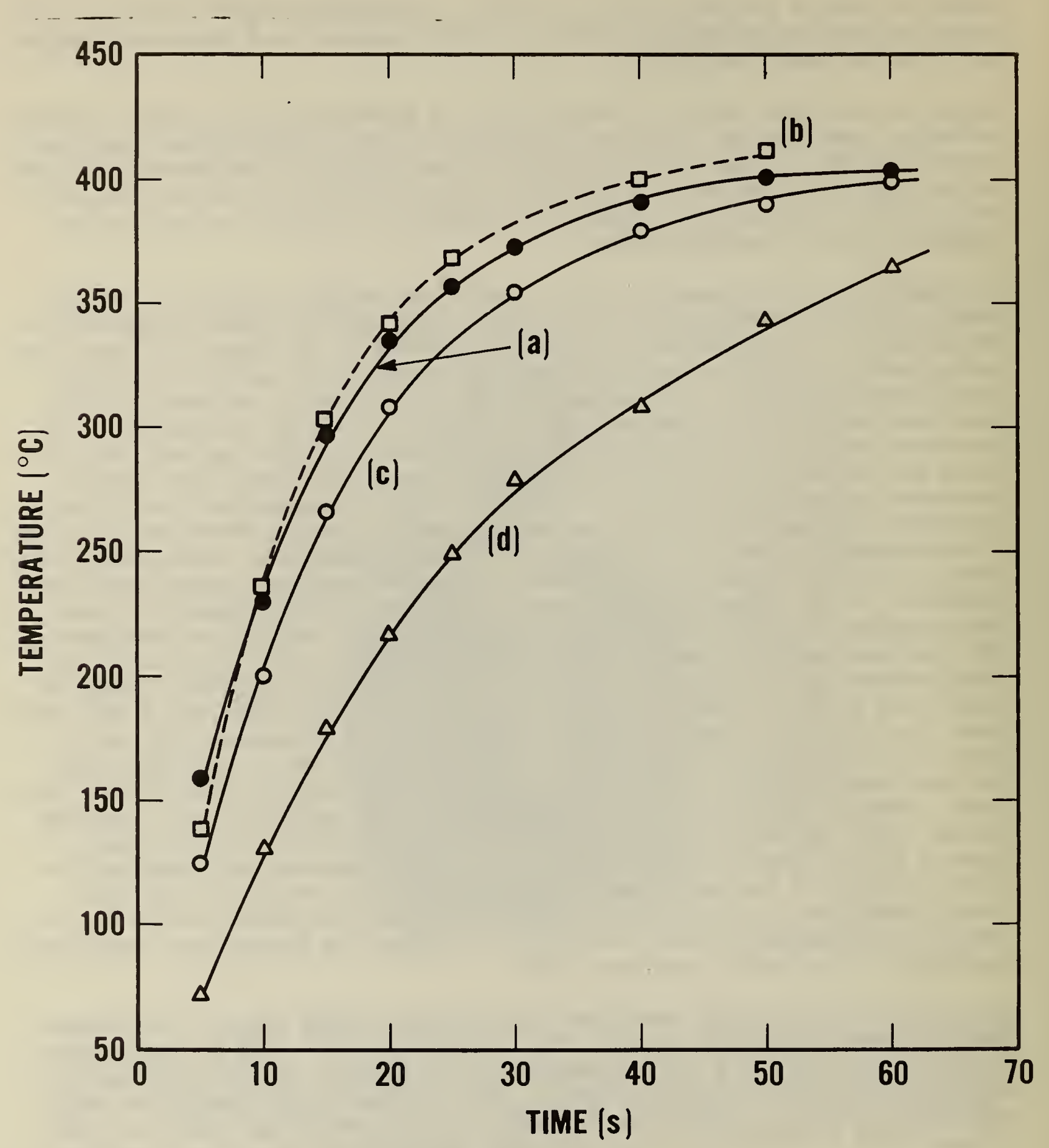

Figure 14. Temperature rise curves for a hybrid package on the hot stage of figure 13. (a) Package face up, hot stage at $400^{\circ} \mathrm{C}$ (normal practice). (b) Package face down, hot stage at $425^{\circ} \mathrm{C}$. (c) Section of $0.003-\mathrm{in}$. wire under face-up package $\left(400^{\circ} \mathrm{C}\right)$. (d) Section of package lead under face-up package $\left(400^{\circ} \mathrm{C}\right)$. 


\section{DETERMINING THE SUSCEPTIBILITY OF THE KOVAR GLASS SEAL \\ TO DAMAGE DURING BONDING}

\subsection{Mechanical Characteristics of Kovar Glass Packages}

There are a number of stresses that are applied to hybrid package seals during production that may damage those seals. Two obvious examples are lead forming and bonding to the leads. This phase of the program is directed toward determining the levels of stress encountered during bonding that may damage the seals, and if found to be destructive, recommending procedural or other changes to retain seal integrity. The approach used was to determine mechanical characteristics by "beam" bending the lead extension inside the package, and any glass-seal cracking was revealed by an $\mathrm{AE}$ sensor coupled to the package.

Figure 15 is a sketch of the experiment which identifies the variables used in equations for beam bending.

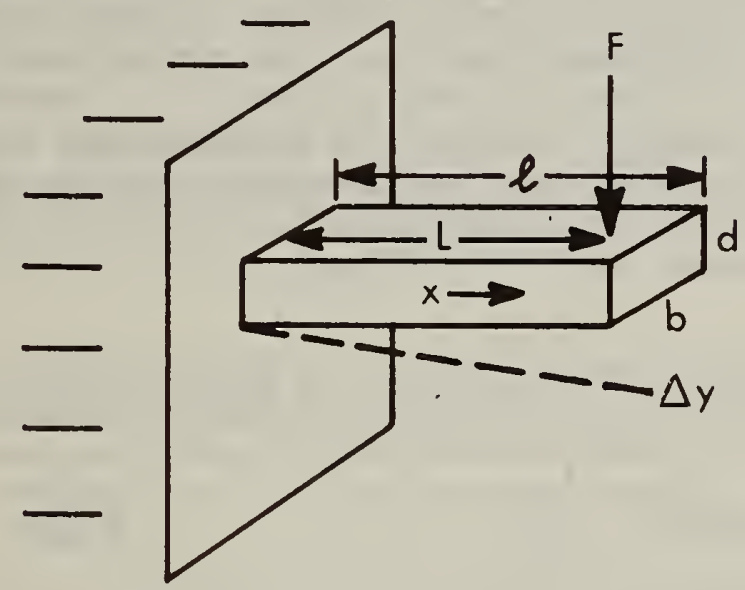

Figure 15. Sketch showing beam-bending variables.

The simplified cantilever beam equation, in which the entire bending Force is applied to one end and the other end is fixed, is [28]:

$$
y=\frac{-F \ell^{3}}{3 E I}=\frac{-4 F \ell^{3}}{b d^{3} E} \text {, }
$$

where:

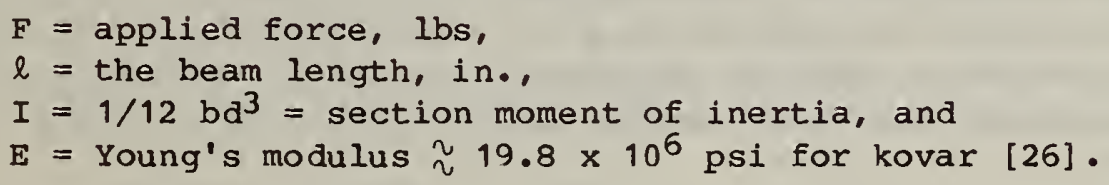

The general equation of deflection at any point, $x$, along a cantilever beam with the force applied at any point, $L$, is: 


$$
y=\frac{F x^{2}}{2 b d^{3} E}(x-3 L)-\frac{F L^{2}}{3 d b^{3} E}(x-L) Q \quad\left(\begin{array}{l}
\text { when } x>L, Q=1 \\
\text { when } x \leq L, Q=0
\end{array}\right)
$$

also $\mathrm{x}=\mathrm{x}$ when $\mathrm{x} \leq \mathrm{L}$, and $\mathrm{X}=\mathrm{L}$ when $\mathrm{x}>\mathrm{L}$.

A program for eq (4) written for programmable calculators having inverse polish logic is given in the appendix. It includes the conditional tests so that only the beam dimensions and applied force need be entered. It should be noted that deflection is proportional to the cube of the lead length and inversely proportional to the cube of the beam thickness. Thus, it is important that the package manufacturer control these dimensions to minimize lead bending and thus any effect it can have on bonding.

The ISHM Hybrid Microelectronic Specification for Metal Packages (ISHM M-SP008, 1978) and most manufacturers' catalogs allow a $\pm 0.002-i n$. variation in lead thickness. This allowed variation can significantly affect bending under a given force as indicated in eqs (3) and (4). Therefore, lead thickness measurements were made on a number of the packages at hand in order to determine the typical range of lead thicknesses actually delivered. These packages were predominately from two manufacturers and included samples from many lots. The thicknesses were as follows:

Table 3. Measured Thicknesses of Hybrid Package Leads.

\begin{tabular}{lcc|cccccc}
\hline $\begin{array}{l}\text { Specified } \\
\text { Thickness, in. }\end{array}$ & \multicolumn{2}{c|}{0.005} \\
$\begin{array}{l}\text { Measured } \\
\text { Thickness, in. }\end{array}$ & 0.0045 & 0.005 & 0.008 & 0.009 & 0.0095 & 0.010 & 0.0105 & 0.011 \\
$\begin{array}{l}\text { Number of } \\
\text { Packages }\end{array}$ & 6 & 2 & 1 & 3 & 14 & 38 & 10 & 1 \\
\hline
\end{tabular}

In a few cases leads of the same package ranged in thickness from 0.009 to $0.011 \mathrm{in.} \mathrm{(within} \mathrm{tolerance)} \mathrm{and} \mathrm{in} \mathrm{width} \mathrm{from} 0.011$ to $0.016 \mathrm{in}$. (uncontrolled). Although the lead thicknesses were all within tolerance, there is an obvious skewing of the distribution towards the thin, more bendable side. A larger number of packages from more manufacturers might show a larger spread.

The depth of lead extension into the package is equally critical with lead thickness for lead bending under a given force. The packages studied showed an interior extension range of from 0.025 to $0.054 \mathrm{in}$. Since they were obtained under various interior specifications, it would not be useful to make a table of their values. However, inspection of various catalogs shows that packages with $0.010-i n$. thick by $0.015-i n$. wide lead cross sections can be ordered with specified internal lead extensions ranging from 0.025 in. to 
$0.110 \mathrm{in} . \frac{+0.01}{-0.005}$. Long leads such as the latter would bend significantly under even the low forces of ultrasonic wedge bonding, presenting nonflat bonding surfaces and resulting in relatively unreliable bonds. The bending would be severe under thermocompression (TC) or thermosonic (TS) bonding forces.

Tests were run to determine the actual characteristics of leads under thermocompression and thermosonic bonding forces. The apparatus used in these initial lead bending experiments is shown in figure 16, with a closeup of the force probe, package, and $A E$ detector shown in figure 17. Measurement of the deflection was made with a 120 power binocular microscope having an eyepiece reticle which was calibrated with a precision stage micrometer. The force was applied by a special thin bonding tool and measured by the gage.

Initial lead-bending tests were run on packages with relatively long leads in order to more easily determine the mechanical characteristics of the kovar. The leads were $0.010 \mathrm{in.} \mathrm{thick} \mathrm{by} 0.014 \mathrm{in}$. wide and $0.10 \mathrm{in}$. long.

The actual deflection was measured and then calculated using the published kovar modulus in the equation. The results of one such test are given in table 4 .

Table 4. Comparison Between Measured and Calculated Bending of Kovar Leads.

$\begin{array}{ccc}\text { Force }(g) \text { Measured Deflect, } & \text { Calculated Deflect, } & \text { Ratio } \\ \text { in. } & \text { in. } & \text { (meas/calc) }\end{array}$

\begin{tabular}{cccc}
\hline 9 & $0.66 \times 10^{-3}$ & $0.28 \times 10^{-3}$ & 2.36 \\
18 & 1.33 & 0.57 & 2.33 \\
25.5 & 1.99 & 0.79 & 2.52 \\
34 & 2.65 & 1.07 & 2.48 \\
36 & $3.3^{*}$ & 1.13 & 2.92
\end{tabular}

*yielding observed.

The large ratios of experimental to calculated bending deflection have been verified on a number of different packages and with leads of different lengths and thicknesses, both with and without gold plating. The discrepancy cannot be attributed to yielding since the beam deflection returned to zero upon unloading for the first four force values in table 4 , and the changes in the ratio are within measurement error. However, the highest force was observed to permanently bend the lead.

The only material constant in eq (4) is the modulus which is listed in tables as $19.8 \times 10^{6} \mathrm{psi}$ for kovar. One would not expect this value to be off by a factor of two with small compositional changes in kovar, since that would bring the value close to that of aluminum, a much weaker material. 

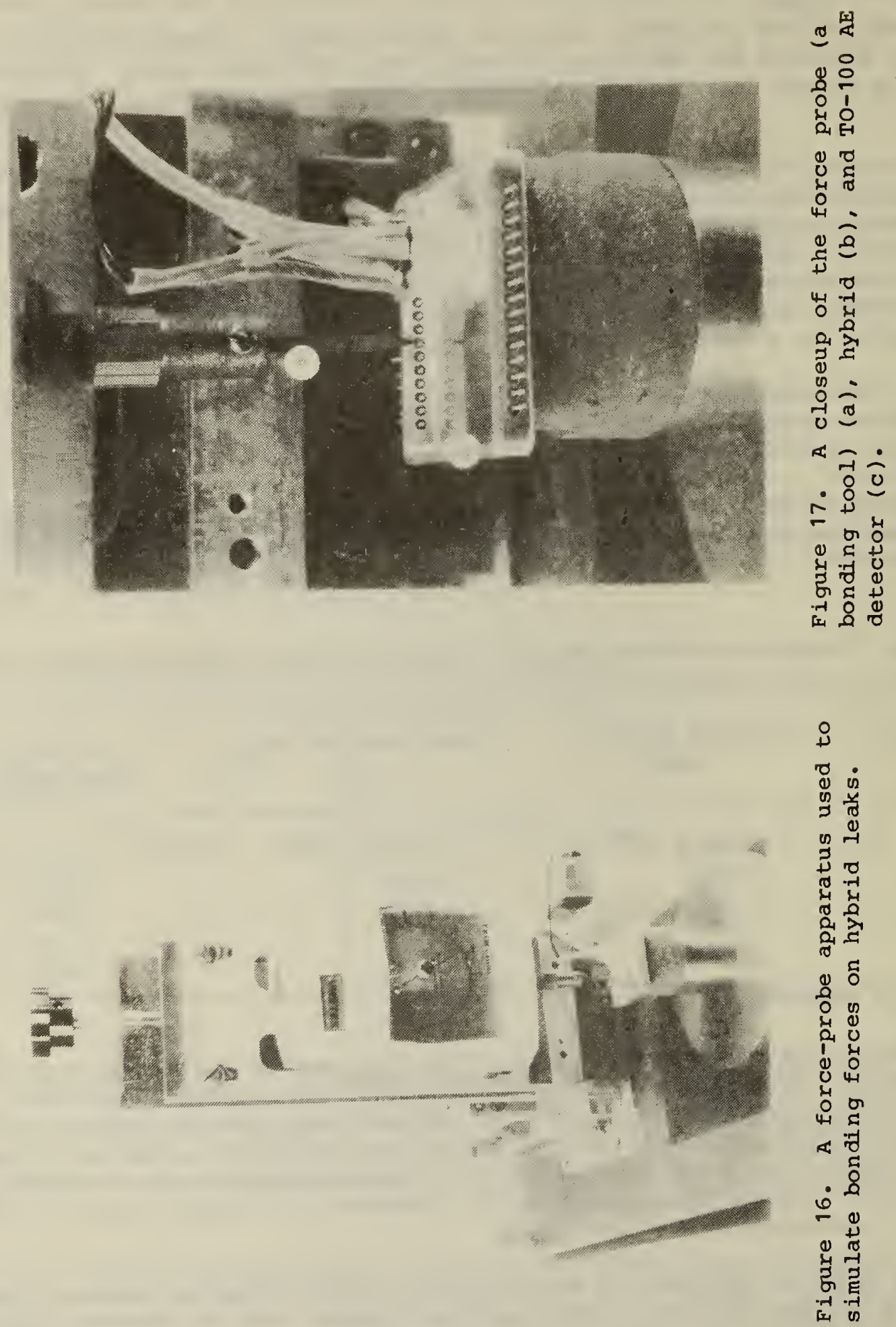
There may be a number of possible explanations for the discrepancy - However, the forces on the glass under the beam may be as high as 40,000 psi and a slight compression of the glass is possible.

An analysis of the effect of such compression of the sealing glass on lead bending was made after the end of this report period and will be given later. However, the results appear to bring the difference between the measured and calculated lead deflection to within about 20 percent and illustrate the importance of including all parts of the glass metal seal when making any stress analysis of hybrid packages.

\subsection{Acoustic Emission Tests to Determine Glass-Seal Damage}

After determining the metallurgical characteristics of kovar leads, acoustic emission instrumented tests were begun in order to establish whether glassseal cracking could be induced by the forces and temperatures of thermocompression and thermosonic bonding to the kovar leads and to establish whether any such cracking could be detected with the TO-100 acoustic emission detector which was waxed to the hybrid package, as was shown in the closeup of figure 17. The block diagram of the $A E$ circuit is given in figure 18 .

Initial tests began on packages having relatively short lead extensions ( $0.035 \mathrm{in.)}$ inside the packages. The force was continuously monitored and recorded each time an $A E$ burst occurred. The first observation was that the leads of certain packages produced numerous $A E$ bursts in the relatively low force range, $\{50 \mathrm{gf}(1 \mathrm{gf}=9.8 \mathrm{mN})$. One such AE burst at a $45-\mathrm{gf}$ load, shown in figure 19, is attributable to a crack in the glass under the lead. Another larger burst that saturated the amplifier is shown in figure 20. A sliver of glass under the lead cracked off at only a 35-gf load. One lead emitted bursts at 19, 39, and 60 gf. Packages that emitted bursts under low loads were observed to have glass wetting or "wicking" irregularly extending outward along the lead past the normal meniscus of the glass bead. This thin glass can crack off with minimal lead bending. There is no evidence thus far that such low-force-induced cracks affect the hermeticity of the seal. However, glass slivers released (or cracked, but left loosely attached during the bending) could certainly act as loose particles if not removed before package sealing. The cracking and slivers generally occur in the package on the underside of the lead where it is difficult or impossible to observe. As a result, it is possible that such broken glass could be the major source of nonmetallic loose particles in susceptible packages. Package specifications should require that the inside glass bead be either flat or have a small uniform meniscus shape.

An unusual form of protection against glass cracking from an uneven meniscus was discovered. One step in the processing of packages after fusing the glass beads involves etch removal of the excess kovar oxide. If a package remains in the etch bath too long or is not completely cleaned, undercutting of the kovar below the glass may occur. Such undercutting is not normally considered desirable and if severe could lower the yield point of the lead. However, the combination of the slightly thinned kovar and the resulting clearance between the most extended part of the glass meniscus apparently serves as protection against glass cracking during slight bending of the lead. Therefore, even though the visual appearance of etch undercut leads is 


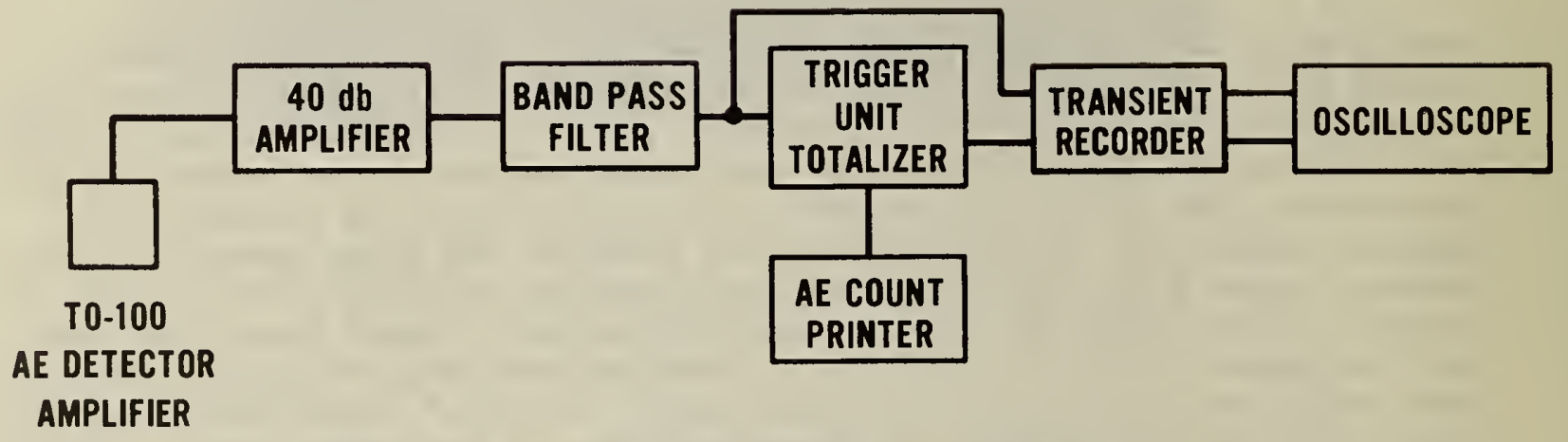

Figure 18. Block diagram of AE measurement equipment. 


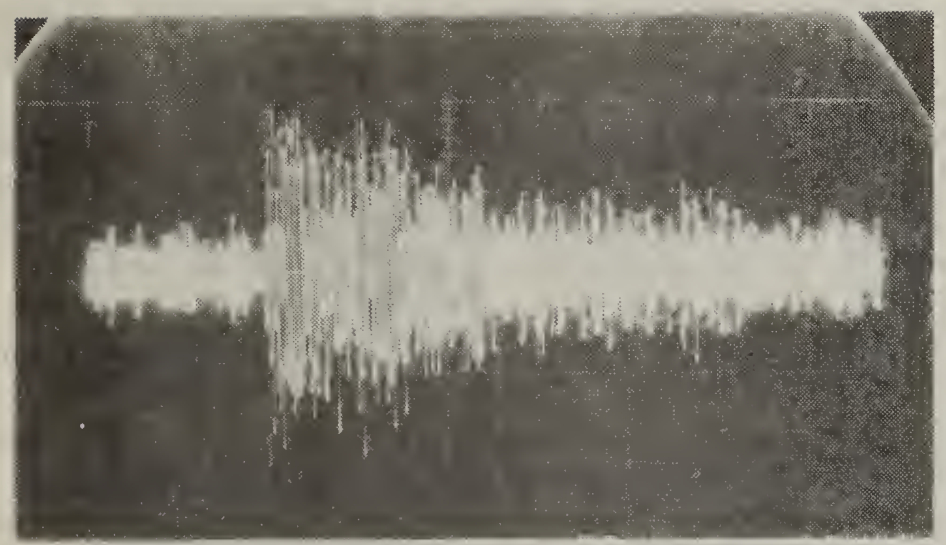

Figure 19. Acoustic emission burst from glass cracking due to a force of 45 gf applied to the internal lead. The horizontal scale is $11 \mu \mathrm{s} /$ div.

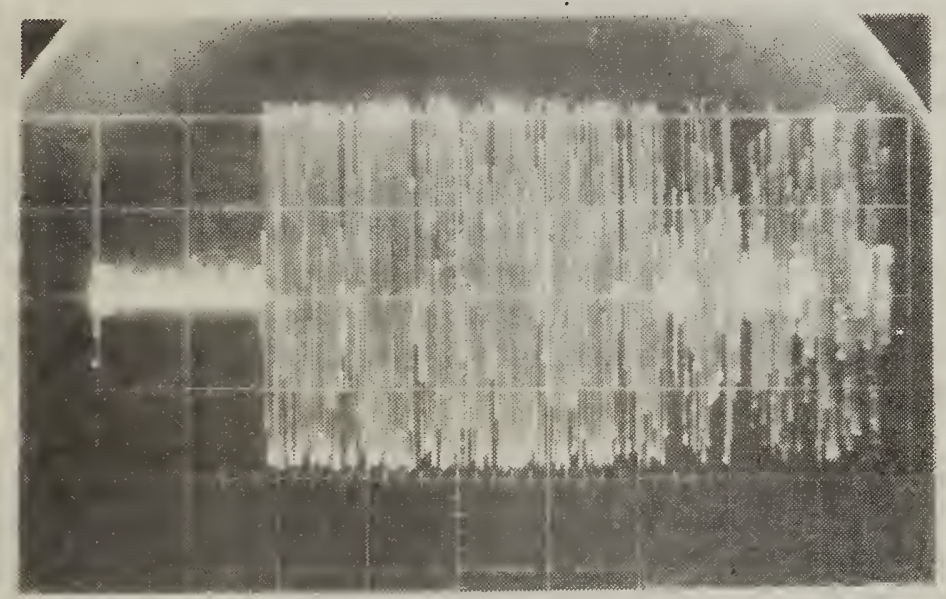

Figure 20. A large acoustic emission burst (saturating the transient recorder) resulting from a small sliver of glass cracking off from the bottom side of the lead resulting in a loose particle. The horizontal scale is 11 $\mu s / d i v$. 
not ideal, such etching appears to protect the glass against cracking under light-load bending. It should be pointed out, however, that the etching undercut patterns could serve as stress risers and result in early fatigue damage in vibration tests (sec. 2.3 ).

Several additional experiments were carried out using higher bending forces on the leads to determine the level required to produce significant glassseal damage. The results indicate that, on the average, significant glass cracking occurs in packages with $0.010-i n$. thick leads extending inside the packages approximately $0.035 \mathrm{in}$. at forces between $150 \mathrm{gf}$ and $200 \mathrm{gf}$. However, severe glass cracking was both detected by $A E$ and visually observed on one seal with a very irregular meniscus at a force of $125 \mathrm{gf}$. The relationship between seal damage, applied force, and the length of lead has not been studied, but will be established during the next stage of the contract.

Other tests were carried out on seals that had been significantly cracked on the outside by bending the leads. These seals were subjected to probe forces on the lead extension inside the package as described above using the apparatus of figure 16. One such lead produced large $\mathrm{AE}$ bursts at 40, 95, 125, and $200 \mathrm{gf}$. These bursts were in the 200 to 500 count range and of sufficient amplitude to saturate the transient recorder input. Another seal that was less damaged than the above one produced several unusual double bursts when stressed, an example of which is shown in figure 21. Presumably, a small crack propagated into a much larger one. The total AE count in this burst was 367 as registered by the digital recorder. It is reasonable to expect that force can be transmitted through a glass seal since the glass is compressible and has a relatively low modulus of $8.9 \times 10^{6}$ psi. This compressibility was discussed at the end of section 6.1 .

The above experiments were a preliminary evaluation to determine any possible thermocompression or thermosonic bonding damage to package seals. The tests were carried out at room temperature where the glass-metal seal is in compression and at its strongest. Future work will extend the seal temperature up to at least $150^{\circ} \mathrm{C}$ where the seal is in tension and should be even more susceptible to damage.

Additional studies of the metallurgical properties of kovar, including hardness tests, sectioning, evaluation of platings, etc., were carried out by Dr. John Smith, NBS, Fracture and Deformation Division. However, this work was done after the end of the fiscal year and will be described in a later report. The author would like to acknowledge many valuable conversations with Dr. Smith concerning the unusual bending characteristics of the small leads as reported above.

\section{Acknow le dgment}

The experimental setup and vibration experiments were performed by $W . J$. Keery of NBS. Most of the jigs, package leak bending fixtures, detector mounts, and force probe apparatus were developed by $\mathrm{W}$. Cullins. The $125^{\circ} \mathrm{C}$ leak test was developed by Stanley Ruthberg. The manuscript was prepared by Jane Walters. The use of the $\mu \mathrm{A}-733$ amplifier chip was recommended by Georgia Riga, Fairchild Semi conductor Corporation. 


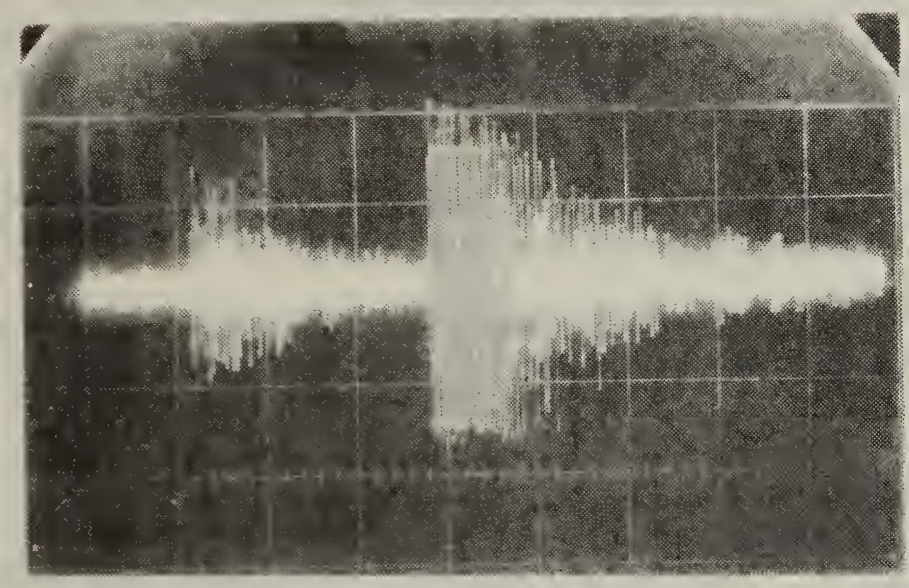

Figure 21. An $A E$ burst at 25 gf applied to the lead from a seal that was damaged on the outside with no damage observed on the inner side of the seal. The double burst presumably resulted from a small glass crack propagating and causing a larger crack. Seals that are damaged on the outside appear to be susceptible to damage during bonding. The horizontal scale is $22 \mu \mathrm{s} /$ div. 
REFERENCES

1. Spanner, J. C., Acoustic Emission Techniques and Applications (Soc. for Nondestructive Testing, 3200 Riverside Drive, Columbus, Ohio 43221, 1974 ).

2. Acoustic Emission, ASTM Technical Publication STP 505 (American Society for Testing and Materials, 1916 Race Street, Philadelphia, Pennsylvania, 1972 ).

3. Harman, G. G., Semiconductor Measurement Technology: Nondestructive Tests Used to Insure the Integrity of Semiconductor Devices, With Emphasis on Acoustic Emission Techniques, NBS Special Publication 400-59 (September 1979).

4. Kumar, A., Failure Analysis of Electric Component Leads, Proc. ATFA-1979, Los Angeles, California, October 8-11, 1979, pp. 28-33.

5. Steinberg, D. S., Vibration Analysis for Electronic Equipment (John wiley \& Sons, New York, 1973).

6. Steinberg, D. S., Circuit Components vs. Random Vibration, Electronic Packaging and Production, 185-187 (July 1975).

7. Steinberg, D. S., Avoiding Vibration in Odd-Shaped Printed Circuit Boards, Machine Design 48, 116-119 (May 1976).

8. Steinberg, D. S., Preventing Vibration Damage in Electronic Assemblies, Machine Design 48, 74-77 (July 1976).

9. Steinberg, D. S., Avoid Failure of PC Board Components, Electronic Design 21, 68-70 (October 1976).

10. Steinberg, D. S., Snubbers Calm PC Board Vibration, Machine Design 49, 71-73 (March 1977).

11. Steinberg, D. S., Countering the Effects of Vibration on Chassis Systems, Electronics 50, 100-102 (Auqust 1977).

12. Sevy, R. W., and Earls, D. L., The Prediction of Internal Vibration Levels of Flight Vehicle Equipment (Limited), Shock and Vibration Bulletin 38 (Supplement), 5-18 (1968).

13. Kohler, B. A., Resonant Beam High "G" Vibration Testing, Shock and Vibration Bulletin 39 (2), 171-76 (1969).

14. Isada, N. M., and Shear, J. C., Vibratory Response of Printed Circuit Boards, Shock and Vibration Bulletin 40 (3), 111-118 (1969).

15. Palmisano, R. R., and Nelly, D. W., Particulate Silicone Rubber: An Effective, Removable Encapsulant for Electronic Packaging, Shock and Vibration Bulletin 46 (4), 277-283 (1976). 
16. Blanks, H. S., Accelerated Vibration Tatigue ifife Testing of Leads and Soldered Joints, Microelectronics and Reliability 15, 213-219 (1975).

17. Morse, P. M., Vibration and Sound (McGraw-Hill Book Co., Inc., New York, 1948 ).

18. Warburton, G. D., The Vibration of Rectangular Plates, Proc. Instr. Mech. Engr. 168, 371-380 (1954).

19. Hearmon, R. F. S., Communications on the Vibration of Rectangular Plates, Proc. Instr. Mech. Engr. 168, 331-384 (1954).

20. Hearmon, R. F. S., The Frequency of Vibration of Rectangular Isotopic Plates, J. Appl. Mechanies ASME 74, 402-415 (1952).

21. Rayleigh, Lord, Theory of Sound, Vol. 1 (MacMillan \& Co., London, 1894 ).

22. Nelson, F. C., Damping PC Boards with Foam Plastic, Circuits Manufacturing 19, 50-53 (November 1979). This paper gives several other references not included in the present study.)

23. Curtis, A. J., Tinling, N. G., and Abstein, H. T., Selection and Performance of Vibration Tests, The shock and Vibration Information Center, SVM-8 (1971).

24. Fackler, w. C., Equivalence Techniques for Vibration Testing, The Shock and Vibration Information Center, SVM-9 (1972).

25. Thomas, R. W., Moisture, Myths and Microcircuits, IEEE Trans. Parts, Hybrids, and Packaging PHP-12, 167-172 (September 1976).

26. See, for instance, Espe, w., Materials of High Vacuur Technology, Vol. 1 (Pergamon Press, New York, 1966).

27. McCormick, J., and Zakraysek, L., A Metallographic Test for Glass-toMetal seal Quality, 17th Annual Proc. Reliability Physics, San FrancisCo, California, April 24-26, 1979, pp. 44-50.

28. See, for example, Griffel, W., Handbook for Formulas for Stress and Strain (Frederick Ungar Publishing Co., New York, 1967). 
APPENDIX

Pocket Calculator Programs for

PC Board Vibration Frequency and

the Bending of Kovar Leads

Title__ Beam Bending and Beam Slope $f(x)$ Page 1 of 2

Progranimer G. G. Harman Date $.8 / 5 / 79$

\begin{tabular}{|l|l|}
\hline Cantilever Beam & Beam II \\
\hline$\Delta y$ lvarE slope $(x)$ & I II \\
\hline
\end{tabular}

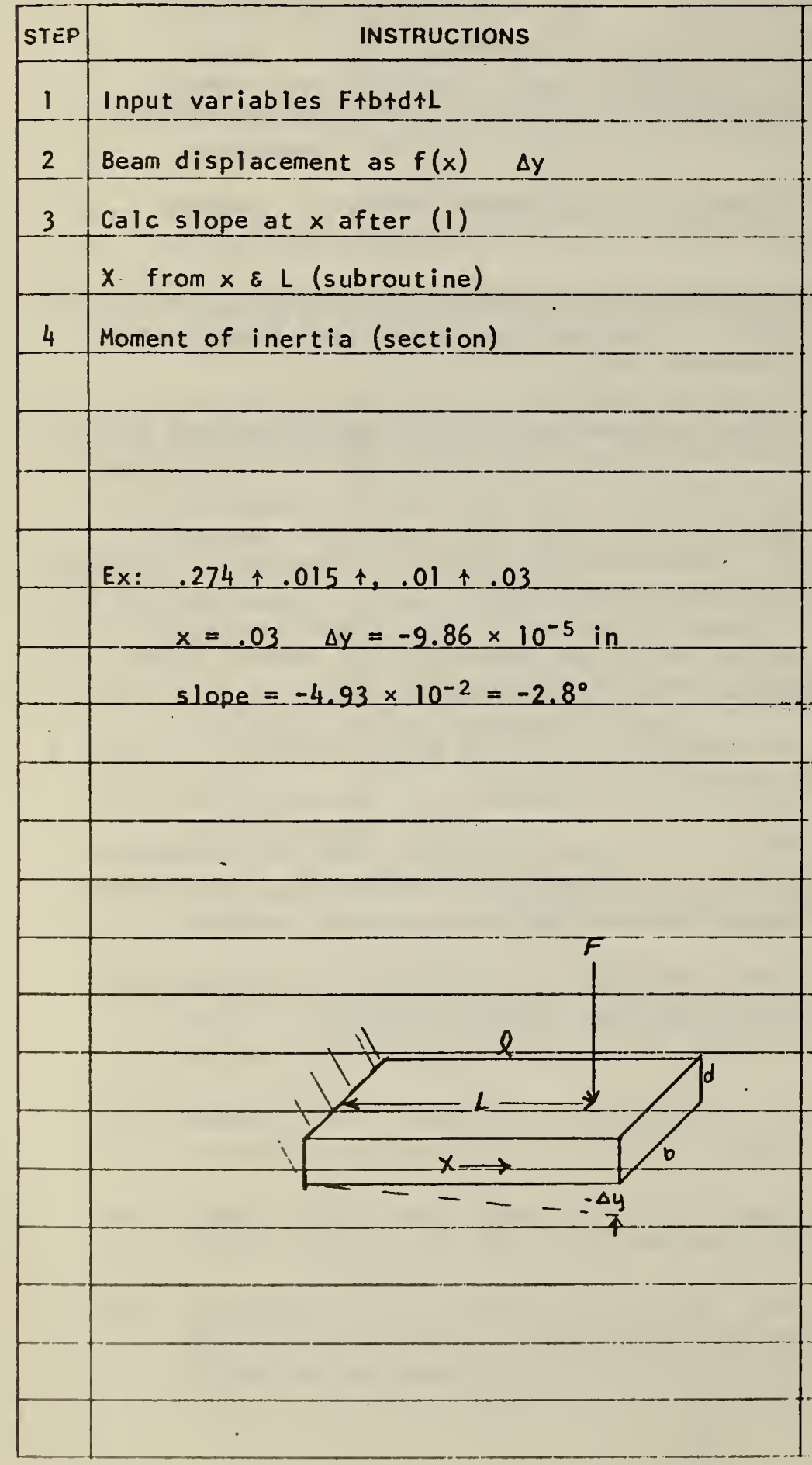

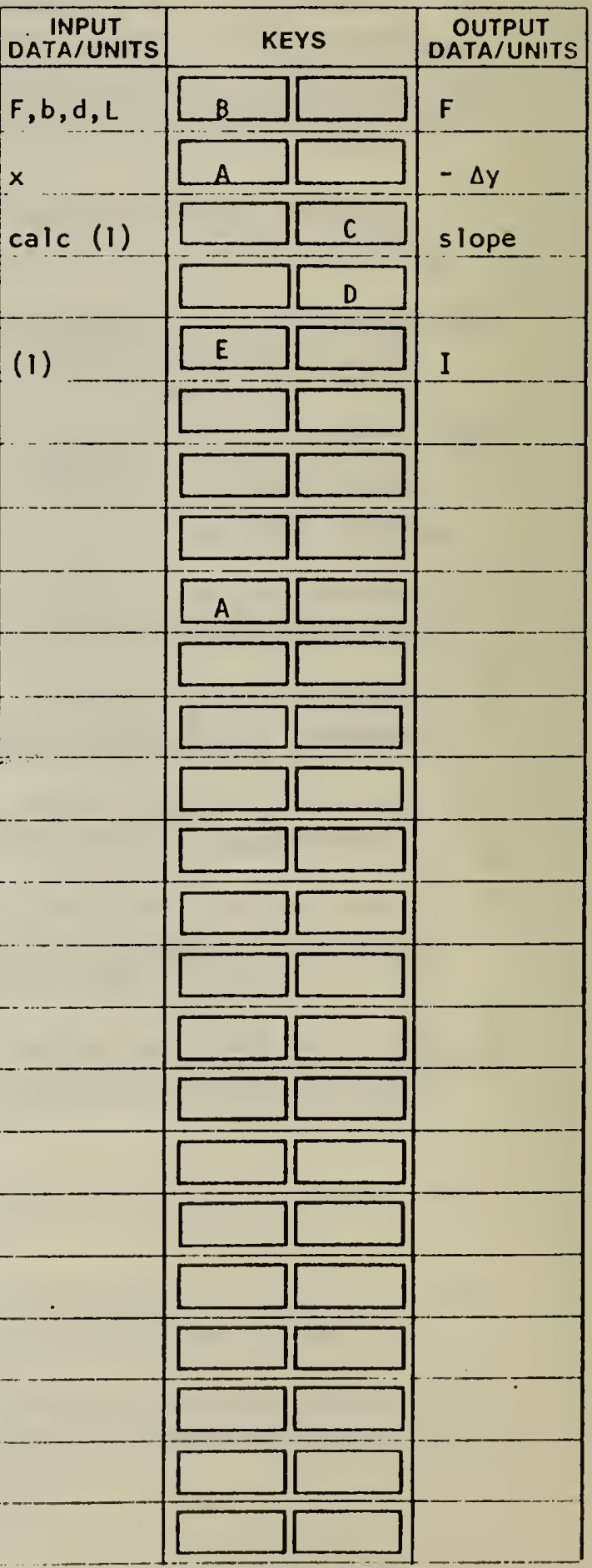


Title Beam Bending Page 22 of 2

SWITCH TO W.PRGM. PRESS [ $[\mathrm{j}$ [PABGM TO CLEAR MEMORY.

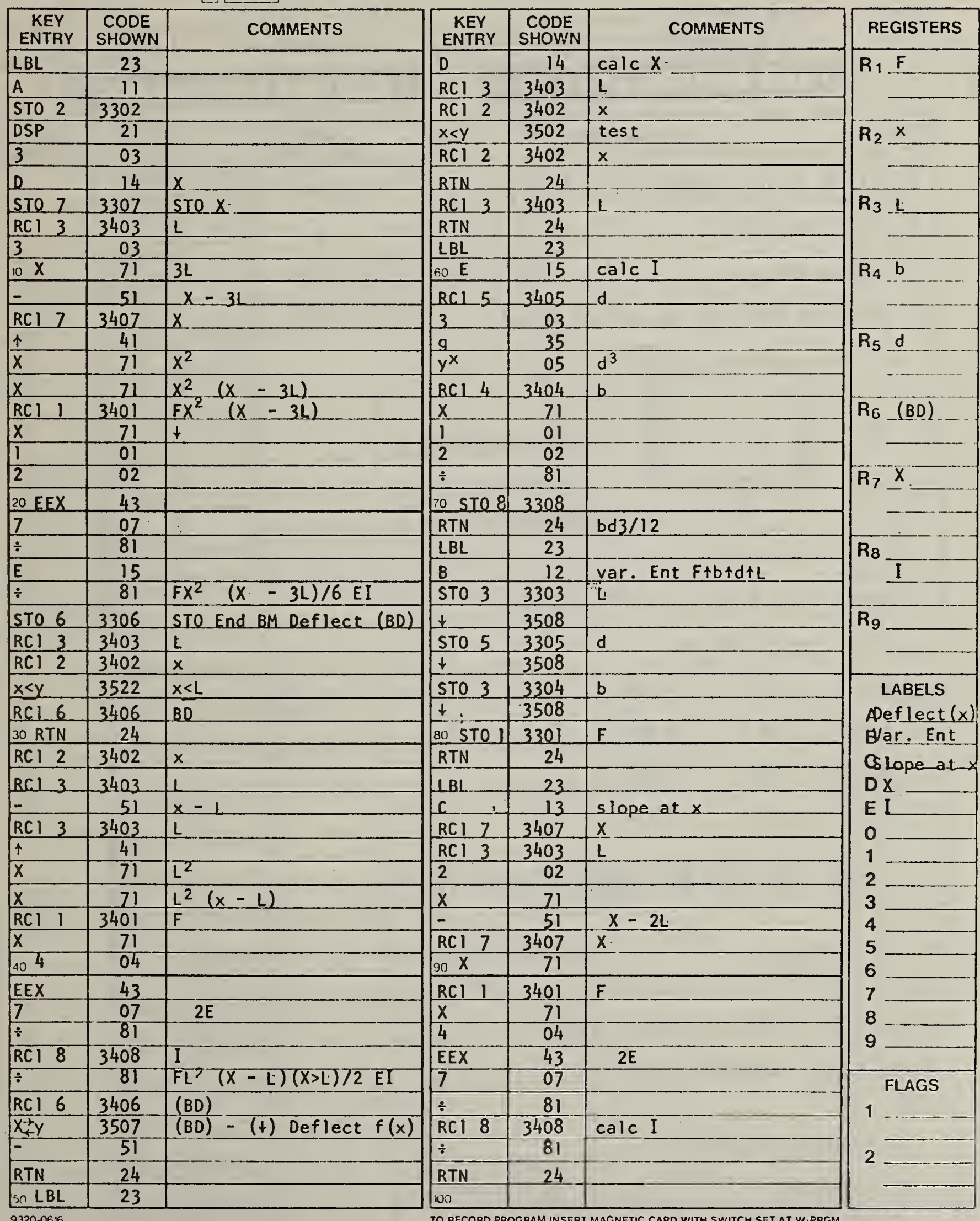


Titie PC Board, Resonant Frequency (Fixed Edges) Page 1 of 2

Programmer G. G. Harman Date $8 / 29 / 79$
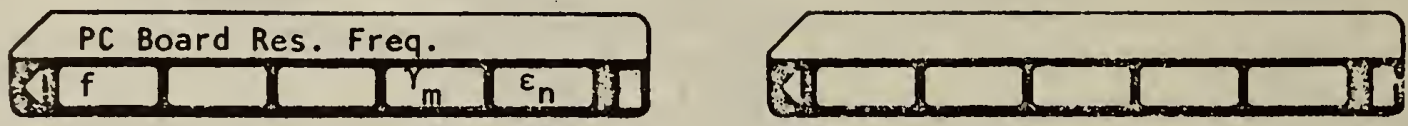

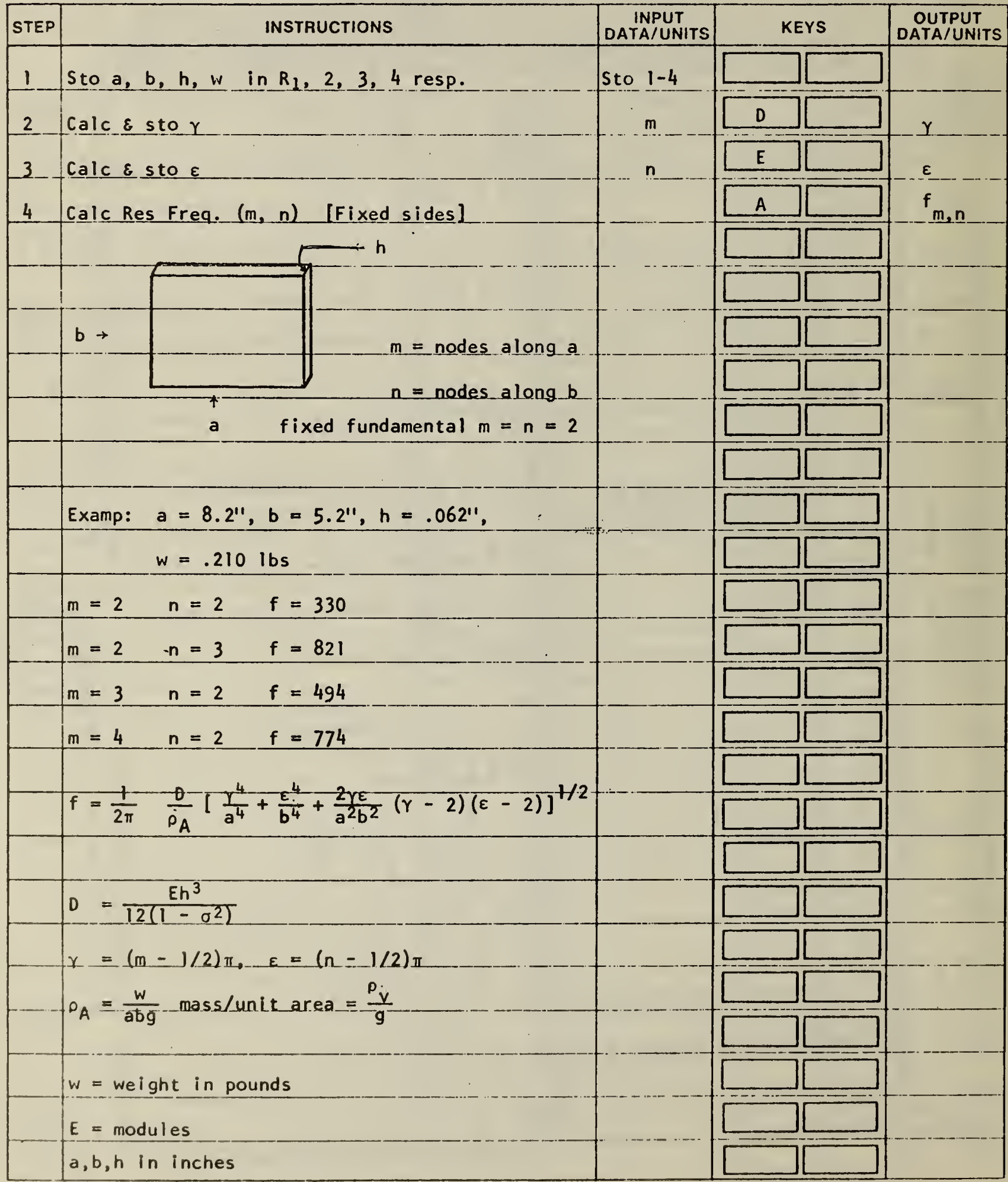


Title PC Board Res $f \mathrm{~nm}^{2}$ all vib modes $m, n, P C-9$

Page_2 of 2 SWITCH TO W PRCM PRESS i] [PRGM] TO CLEAR MEMORY.

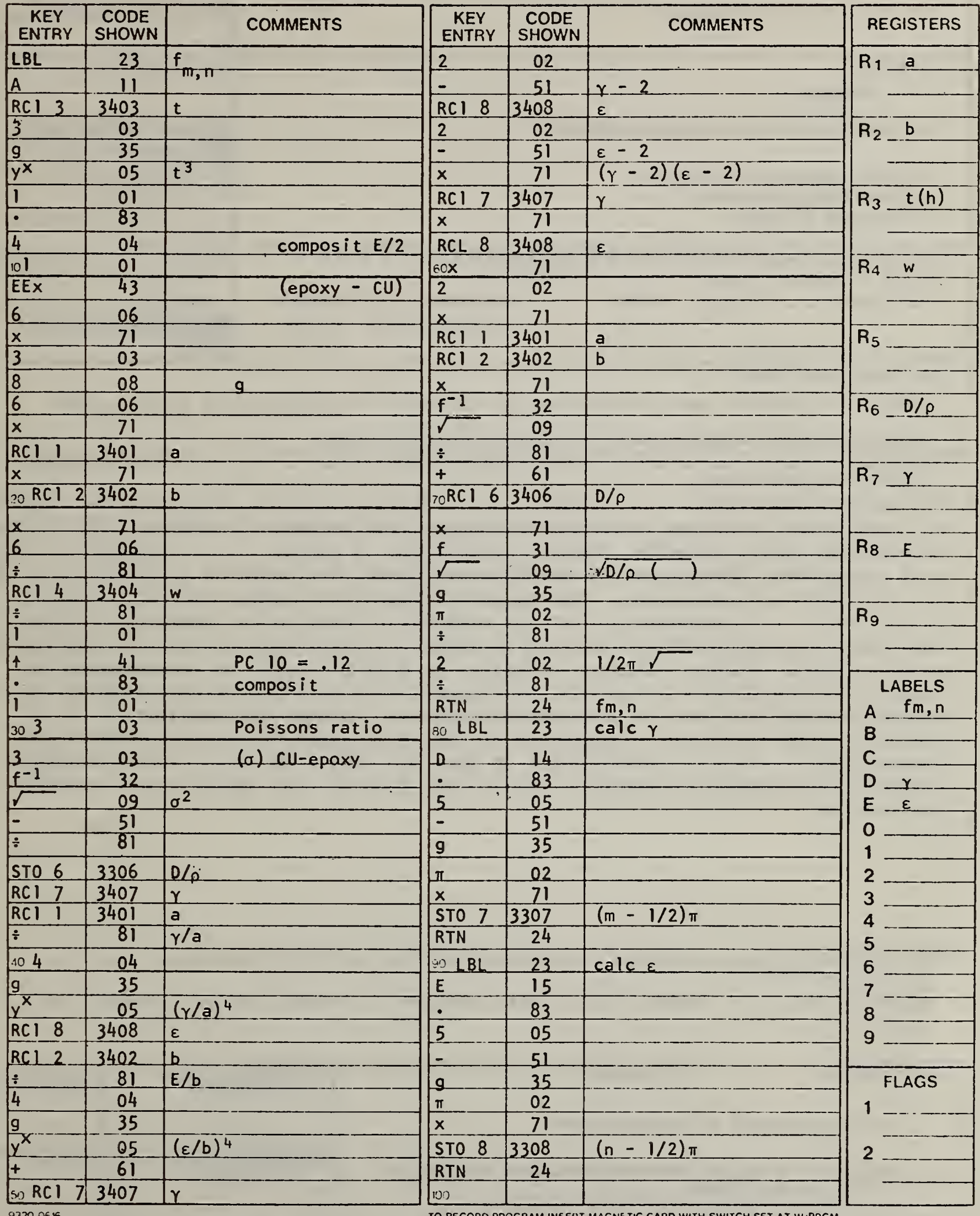


NBS-114A IREV. 9.78 ,

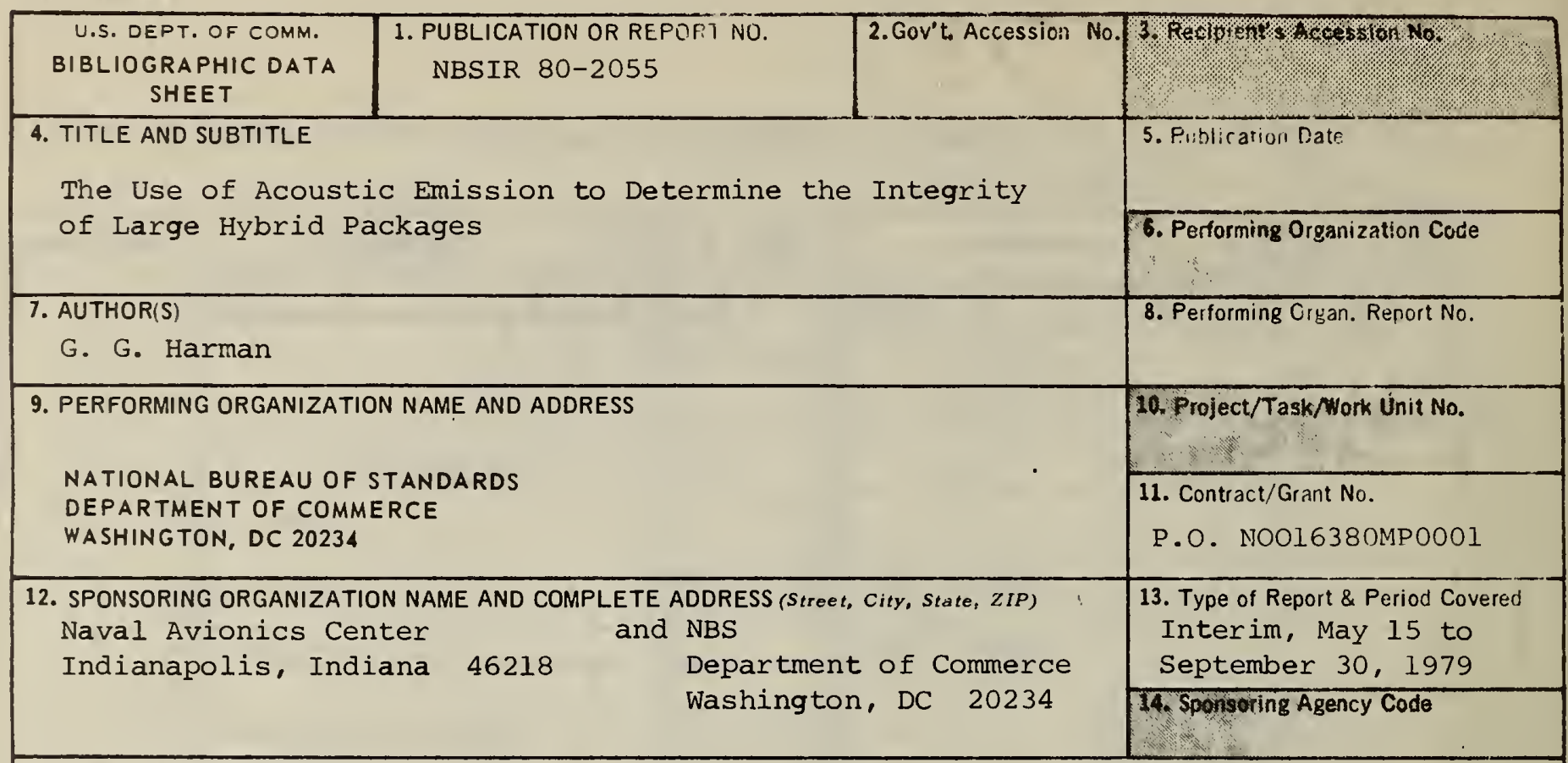

15. SUPPLEMENTARY NOTES

Additional support was provided by the Office of Nondestructive Testing, NBS

$\square$ Document describes a computer program; SF-185, FIPS Software Summary, is attached.

16. ABSTRACT (A 200-word or less factual summary of most significant information. If document includes a significant bibliography or literature survey, mention it here.)

The general objective of the program was to develop tests to determine the integrity of large hybrid packages under various thermal and mechanical stresses that may be encountered during assembly, during installation in systems, or in operation. Several measurement techniques are being investigated, but emphasis is placed on acoustic emission test procedures. The specific objectives studied during the initial period were: (1) determination of the effects of avionics environmental vibration on the seals of hybrid packages mounted on printed-circuit (PC) boards; (2) development of an acoustic emission detector sensitive to surface waves, but insensitive to vibration-induced cable noise; (3) development of a high-temperature (125\% C) 0 penpackage helium leak test to observe marginal seal damage; (4) development of an acoustic emission test for inspection of hybrid packages during high-temperature thermal shock; and (5) determination of possible damage to seals during thermocompression and thermosonic bonding, during lead forming, and during other assembly operations.

17. KEY WORDS (aix to twelve entries; alphabetical order; capitafize only the first letter of the first key word unless a proper name; separated by semicolons)

Acoustic emission; hermeticity; hybrid package; microelectronics; thermal shock; vibration.

18. AVAILABILITY [x] Unlimited

For Official Distribution. Do Hot Release to NTIS

Order From Sup. of Doc., U.S. Government Printing Office, Washington, DC 20402, SD Stock No. SNÓO3-003-

[\%. Order From National Technical Information Service (NTIS), Springfield, VA. 22161

\begin{tabular}{|l|c|}
$\begin{array}{l}\text { 19. SECURITY CLASS } \\
\text { (THIS REPORT) } \\
\text { UNCLASSIFIED }\end{array}$ & $\begin{array}{c}\text { 21. NO. OF } \\
\text { PRINTED HAGES }\end{array}$ \\
\hline $\begin{array}{l}\text { 20. SECURITY CLASS } \\
\text { (THIS PAGE) }\end{array}$ & 22. Price \\
UNCLASSIFIED & \\
\hline
\end{tabular}




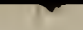


